ENVIRONMENTAL RESTORATION PROGRAM

\section{Technical Evaluation Summary of the In Situ Vitrification Melt Expulsion at the Oak Ridge National Laboratory on April 21, 1996, Oak Ridge, Tennessee}

\author{
PECE: \\ DEC O $5 \%$ \% \\ OSTI
}

This document has been approved by the ORNL Technical Information Office for release to the public. Date: $11 / 6 / 96$ 
This report has been reproduced directly from the best available copy.

Available to DOE and DOE contractors from the Office of Scientific and Technical Information, P.O. Box 62, Oak Ridge, TN 37831; prices available from 423-576-8401 (fax 423-576-2865).

Available to the public from the National Technical Information Service, U.S. Department of Commerce, 5285 Port Royal Rd., Springfield, VA 22161. 


\section{DISCLAMIER}

Portions of this document may be illegible in electronic image products. Images are produced from the best available original document. 


\section{DISCLAIMER}

This report was prepared as an account of work sponsored by an agency of the United States Government. Neither the United States Government nor any agency thereof, nor any of their employees, makes any warranty, express or implied, or assumes any legal liability or responsibility for the accuracy, completeness, or usefulness of any information, apparatus, product, or process disclosed, or represents that its use would not infringe privately owned rights. Reference herein to any specific commercial product, process, or service by trade name, trademark, manufacturer, or otherwise does not necessarily constitute or imply its endorsement, recommendation, or favoring by the United States Government or any agency thereof. The views and opinions of authors expressed herein do not necessarily state or reflect those of the United States Government or any agency thereof. 
,

(

: 
Energy Systems Environmental Restoration Program

\title{
Technical Evaluation Summary \\ of the In Situ Vitrification Melt Expulsion \\ at the Oak Ridge National Laboratory \\ on April 21, 1996, \\ Oak Ridge, Tennessee
}

Date Issued—November 1996

\author{
Prepared for the \\ U.S. Department of Energy \\ Office of Environmental Management \\ under budget and reporting code EW 20 \\ Environmental Management Activities at the \\ OAK RIDGE NATIONAL LABORATORY \\ Oak Ridge, Tennessee 37831-8169 \\ managed by \\ LOCKHEED MARTIN ENERGY SYSTEMS, INC. \\ for the \\ U.S. DEPARTMENT OF ENERGY \\ under contract DE-AC05-84OR21400
}




\section{ACKNOWLEDGMENTS}

This technical evaluation was performed by a group of in situ vitrification project personnel with significant input from Brian Spalding, Mike Naney, Steve Cline, and Mary Anna Bogle of the Environmental Sciences Division, Oak Ridge National Laboratory; John Tixier, of Battelle Pacific Northwest Laboratory; and Craig Timmerman of Geosafe, Inc. 


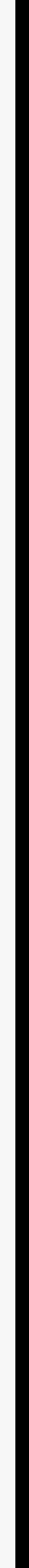




\section{PREFACE}

This Technical Evaluation Summary of the In Situ Vitrification Melt Expulsion at the Oak Ridge National Laboratory on April 21, 1996, was prepared at the request of the Department of Energy as a supporting reference document for the Final Unusual Occurrence Report to fully explore the probable causes that lead to the subject incident.

This work was performed under Work Breakdown Structure 1.4.12.6.1.07 (Activity Data Sheet 3307, "Waste Area Grouping 7 In Situ Vitrification"). This document provides the Environmental Restoration Program with the technical information on the performance of the in situ vitrification treatability study operations at ORNL pit 1 up to and including the time of the melt expulsion incident.

This document also attempts to diagnose the causes of the melt expulsion event, the consequent damages to equipment, the radiological impacts of the event, and the equipment design modifications and procedural changes necessary for future safe ISV operations. A companion document, Environmental Health and Safety Independent Investigation of the In Situ Vitrification Melt Investigation of the In Situ Vitrification Melt Expulsion at the Oak Ridge National Laboratory, Oak Ridge, Tennessee (ORNL/ER-371) has also been issued; that report focuses on the results of an independent team's investigation of the project's operational procedures, management, and oversight activities rather than the physical mechanisms leading to the melt expulsion event. 



\section{CONTENTS}

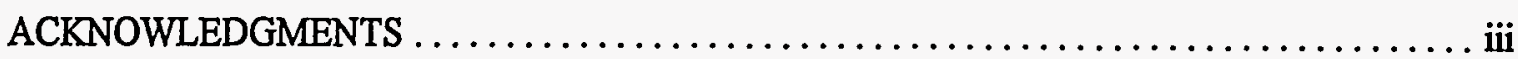

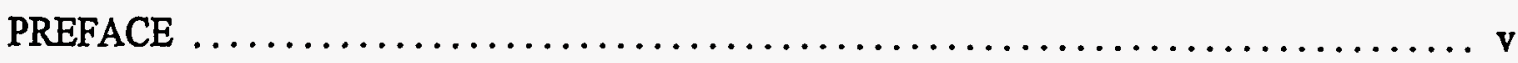

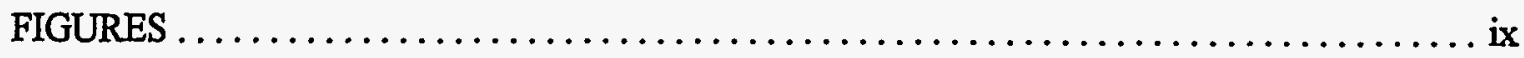

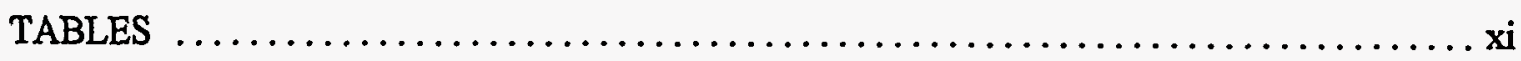

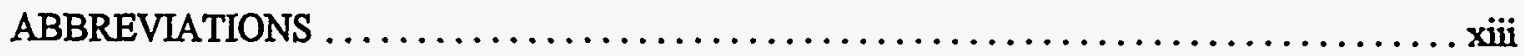

EXECUTIVE SUMMARY $\ldots \ldots \ldots \ldots \ldots \ldots \ldots \ldots \ldots \ldots \ldots \ldots \ldots \ldots \ldots \ldots \ldots \ldots$

1. EVENT SUMMARY DESCRIPTION $\ldots \ldots \ldots \ldots \ldots \ldots \ldots \ldots \ldots \ldots \ldots \ldots \ldots \ldots$

2. MAJOR CONCERNS DURING AND AFTER THE MELT EXPULSION INCIDENT $\ldots \ldots 1$

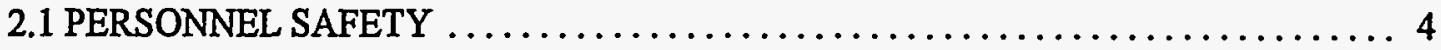

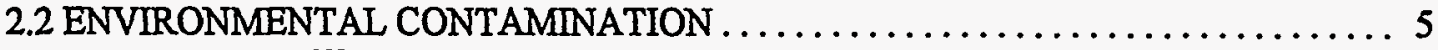

2.2.1 Activity of ${ }^{137} \mathrm{Cs}$ in Samples of Glass Expelled From ISV Hood . . . . . . . . . . 6

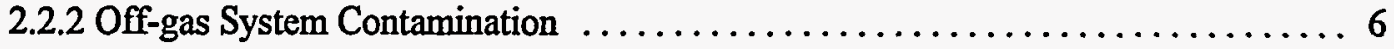

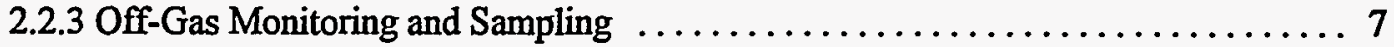

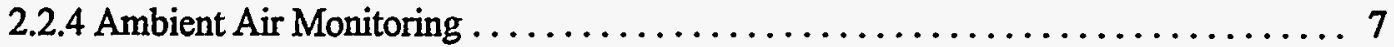

2.2.5 Uncontrolled Air Release Estimate ............................ 9

2.2.6 Distribution and Dispersion of ISV Glass $\ldots \ldots \ldots \ldots \ldots \ldots \ldots \ldots \ldots, 9$

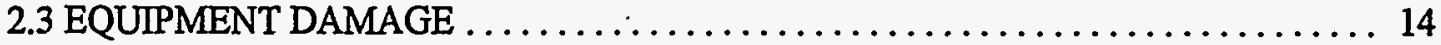

2.3.1. Damage on Hood Perimeter ................................ 14

2.3.2 Damage on Hood Work Platform ............................. 16

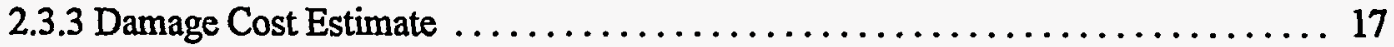

3. PROPERTIES OF MELTED SOIL PRESENT DURING THE MELT EXPULSION

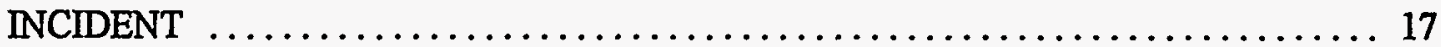

4. PROCESS PERFORMANCE AND PERFORMANCE DATA SUMMARY $\ldots \ldots \ldots \ldots .20$

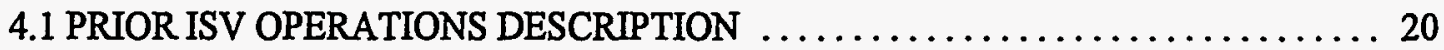

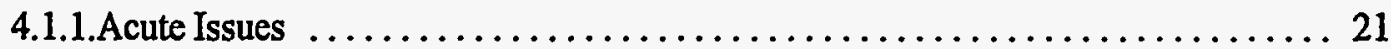

4.1.2. Chronic Issues $\ldots \ldots \ldots \ldots \ldots \ldots \ldots \ldots \ldots \ldots \ldots \ldots \ldots \ldots \ldots \ldots \ldots \ldots \ldots \ldots \ldots \ldots \ldots \ldots \ldots, 22$

4.1.3 Operational Acceptance Test (OAT) Evaluation .................... 25

4.2 ISV PROCESS PERFORMANCE DATA BEFORE AND DURING MELT

EXPULSION INCIDENT $\ldots \ldots \ldots \ldots \ldots \ldots \ldots \ldots \ldots \ldots \ldots \ldots \ldots \ldots \ldots \ldots \ldots, 25$

4.2.1 Electrode Depth Versus Time ............................... 25

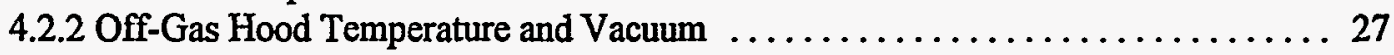

4.2.3 Electrical Power Characteristics ............................... 27

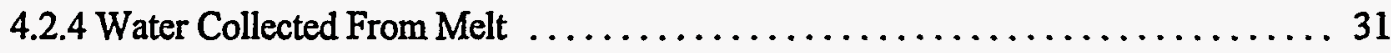

4.2.5 Water Table Responses Before and After Melt Expulsion .............. 31 


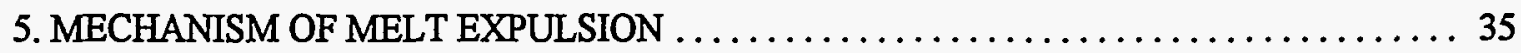

5.1 SOIL POROSITY FOR OFF-GAS CONDUCTION $\ldots \ldots \ldots \ldots \ldots \ldots \ldots \ldots, 38$

5.2 MELT HYDROSTATIC PRESSURE $\ldots \ldots \ldots \ldots \ldots \ldots \ldots \ldots \ldots \ldots \ldots, \ldots \ldots \ldots$

5.3 SINTERED ZONE PROPERTIES $\ldots \ldots \ldots \ldots \ldots \ldots \ldots \ldots \ldots \ldots \ldots, 40$

5.4 COLD CAP FORMATION $\ldots \ldots \ldots \ldots \ldots \ldots \ldots \ldots \ldots \ldots \ldots \ldots, 40$

5.5 PRESSURUZATION BY STEAM $\ldots \ldots \ldots \ldots \ldots \ldots \ldots \ldots \ldots \ldots \ldots \ldots, 40$

6. ROOT CAUSE OF PIT 1 MELT EXPULSION INCIDENT $\ldots \ldots \ldots \ldots \ldots \ldots \ldots \ldots, \ldots$

7. TECHNIQUES TO AVOID FUTURE MELT EXPULSIONS $\ldots \ldots \ldots \ldots \ldots \ldots \ldots \ldots 42$

7.1 DRAWDOWN PERCHED GROUNDWATER IN PIT $1 \ldots \ldots \ldots \ldots \ldots \ldots \ldots 42$

7.2 EMPLACE MONITORED VENT PIPES BENEATH MELT BODY $\ldots \ldots \ldots \ldots \ldots, 42$

7.3 SUBSURFACE PRESSURE MONITORING $\ldots \ldots \ldots \ldots \ldots \ldots \ldots \ldots \ldots, 43$

7.4 HOLD ELECTRODES ABOVE PIT BOTTOM $\ldots \ldots \ldots \ldots \ldots \ldots \ldots \ldots . \ldots 4$

8. SAFETY IMPROVEMENTS FOR FUTURE ISV MELT EXPULSIONS $\ldots \ldots \ldots \ldots \ldots 44$

8.1 PERSONNEL SAFETY CHANGES $\ldots \ldots \ldots \ldots \ldots \ldots \ldots \ldots \ldots \ldots \ldots, 44$

8.1.1 Predetermined Pressure Relief Zones . . . . . . . . . . . . . . . . . . . . . . 44

8.1.2 Off-Gas Deflection Barrier ............................... 45

8.1.3 Elimination of Tasks in Danger Zone . . . . . . . . . . . . . . . . . . . 45

- 8.1.4 Automation of Monitoring and Adjustment Tasks ................... 45

8.1.5 Protection of Personnel During Necessary Tasks $\ldots \ldots \ldots \ldots \ldots \ldots \ldots \ldots .47$

8.1.6 Definition of Hazard Zones and Times $\ldots \ldots \ldots \ldots \ldots \ldots \ldots \ldots \ldots \ldots, 48$

8.2 EQUIPMENT PROTECTION ................................. 49

8.3 EMERGENCY RESPONDER TRAINING AND PROCEDURES . . . . . . . . . 49

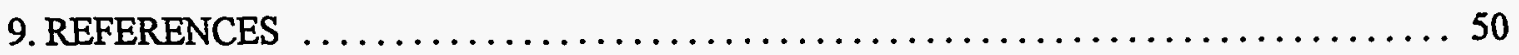




\section{FIGURES}

1. Aerial photograph of ORNL ISV site on April 22, 1996, with notations showing locations of key equipment and pertinent incident areas $\ldots \ldots \ldots \ldots \ldots \ldots 2$

2. Sequence of video monitoring images captured at five minute intervals immediately before to ten minutes after the ISV incident of April 21, $1996 \ldots \ldots \ldots \ldots .3$

3. Distribution of ${ }^{137} \mathrm{Cs}$ in ISV off-gas and equipment following the incident

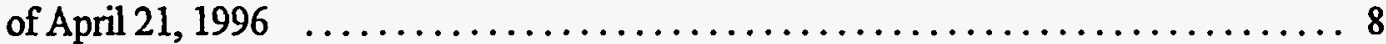

4. Flow of ISV glass from under off-gas containment hood following the incident of April 21, 1996

5. ISV glass fibers frozen in forming process on ground surface near edge

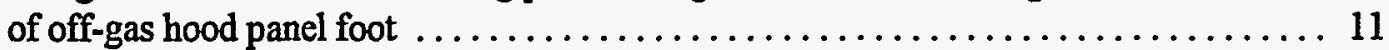

6. Expelled ISV glass glob on ground surface just to east of off-gas hood $\ldots \ldots \ldots \ldots \ldots 12$

7. Hair-like form of ISV glass expelled approximately 20 feet east of off-gas

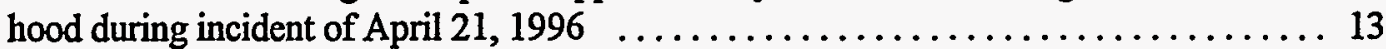

8. Estimation of distribution of ISV expelled glass within and around off-gas collection hood after April 21, 1996 incident ..................... 15

9. Geometric configuration and dimensions assumed for calculation of ISV melt body size ....................................... 18

10. Depth of ISV electrode penetration into the ORNL melt as a function of time and its relation to groundwater elevation within and around pit $1 \ldots \ldots \ldots \ldots \ldots 26$

11. Off-gas hood plenum temperature during the 20 hours immediately before the ISV melt expulsion incident of April 21, 1996, 18:12 .............. 28

12. Vacuum within the ISV off-gas collection hood during the 20 hours preceding the ORNL ISV incident of April 21, 1996, 18:12 .................... 29

13. Electrical power and cumulative energy applied to the ORNL ISV melt over

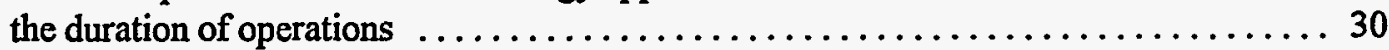

14. Electrical power applied to the ORNL ISV melt during the twenty hours preceding

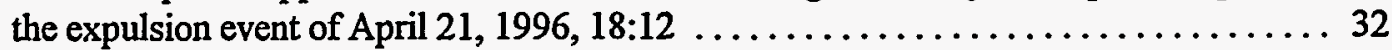

15. Cumulative volume and solution levels in ISV off-gas scrub system 1 during

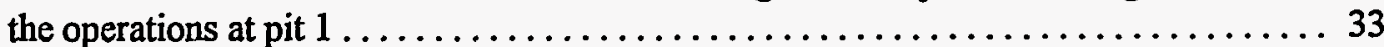

16. Watertable elevations within and around ORNL pit 1 and precipitation during ISV operation relative to the April 21, 1996, expulsion incident . . . . . . . . . . . 34

17. Cross-section of ORNL pit 1 showing melt depth, perched groundwater, monitoring wells, and thermocouple positions immediately before the incident of April 21, 1996 .. 36

18. Conceptual model of ISV off-gas vapor pathways around a body of molten soil . . . . 37

19. Conceptualization of steam-bubble mediated expulsion of molten glass during the April 21, 1996 incident at ORNL 


\section{TABLES}

1. Elemental composition of ISV product at ORNL pit 1 after the Operational Acceptance Test (OAT) and the melt expulsion incident. . . . . . . . . . . . 19 


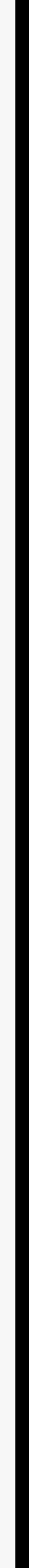




\section{ABBREVIATIONS}

DAS

DOE

EDT

EPA

HEPA

ISV

$\mathrm{kWh}$

LMES

MAS

MM5

MW

NGVD

OAT

ORNL

PNNL

T100P

UST data acquisition system

Department of Energy

eastern daylight time

Environmental Protection Agency

high efficiency particulate air

in situ vitrification

kilowatt hour

Lockheed Martin Energy Systems

material addition system

modified method 5

megawatt

national geodetic vertical datum

operational acceptance test

Oak Ridge National Laboratory

Pacific Northwest National Laboratory

temperature of 100 poise viscosity

underground storage tank 


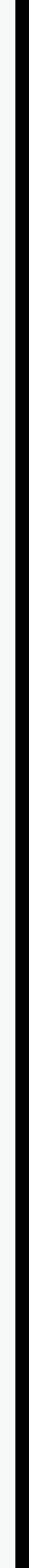




\section{EXECUTIVE SUMMARY}

On April 21, 1996, at 6:12 p.m., approximately 20 tons of molten glass were expelled from a 216ton body of molten (approximately $1600^{\circ} \mathrm{C}$ ) radioactively contaminated soil (containing $2.4 \mathrm{Ci}$ of ${ }^{137} \mathrm{Cs}$ ) at a field site at the Oak Ridge National Laboratory in Oak Ridge, Tennessee.

The melt expulsion was caused by pressurized steam venting rapidly through, rather than by the desired path around, the molten body. During the previous 17 days, an old seepage pit was undergoing in situ vitrification (ISV) to convert it from porous, leachable soil into a monolithic, impermeable vitreous waste form. Approximately $2 \mathrm{MW}$ of electrical power was being delivered to the molten body, which was contained in the ground and covered with a stainless steel hood maintained under negative pressure to collect, filter, scrub, and monitor off-gas.

Off-gas into the hood was rapidly heated by the melt expulsion from a typical operating temperature of $250^{\circ} \mathrm{C}$ to over $1000^{\circ} \mathrm{C}$ with an associated surge of pressure sufficient to lift the $15,000-1 \mathrm{~b}$ hood approximately $12 \mathrm{in.} \mathrm{off} \mathrm{the} \mathrm{ground} \mathrm{at} \mathrm{least} \mathrm{on} \mathrm{one} \mathrm{end.} \mathrm{A} \mathrm{small} \mathrm{pool} \mathrm{of} \mathrm{molten} \mathrm{glass} \mathrm{was} \mathrm{able} \mathrm{to} \mathrm{flow}$ up to $3 \mathrm{ft}$ outside the hood while it was raised off the ground. The escaping hot off-gas and molten glass ignited several small fires in combustible components near or attached to the external hood frame (e.g, wire insulation, plastic hose, fiberglass trays). Fire department personnel responded to the emergency notification within minutes but were not needed because the small fires self-extinguished within an hour. Four project personnel were performing tasks at the site at the time of the melt expulsion; none were injured or contaminated during the melt expulsion incident. Air samples taken from the hood perimeter near the small fires failed to detect any airborne contamination.

Subsequent analyses of ambient air collected by the project's three air samplers did not reveal any airborne contamination. However, analysis of off-gas sampled directly from the ISV hood, coupled with an estimate of the volume of off-gas released from the pressurized hood, revealed that a maximum of $0.13 \mu \mathrm{Ci}$ of ${ }^{137} \mathrm{Cs}$ could have been released. This activity of ${ }^{137} \mathrm{Cs}$ could have delivered a hypothetical and unmeasurable dose of $0.02 \mu \mathrm{rem}$ to the nearest private residence outside the Oak Ridge Reservation under worst-case meteorological conditions.

Subsequent analyses of off-gas processing filters revealed that they contained $99.7 \%$ of all off-gas radioactivity. Moreover, the residual molten material was found to contain $99.9981 \%$ of the ${ }^{137} \mathrm{Cs}$ being processed at the time of the melt expulsion. Small fragments of expelled glass were found within 300 $\mathrm{ft}$ of the off-gas hood; they apparently formed when the high-velocity off-gas was escaping under the hood and across the pool of molten glass. Many light pieces of fiberglass were apparent as well as a few globular clusters. Subsequent cleanup efforts revealed a total of only a few pounds of these contaminated fibers at the site.

All expelled glass particles were found to have a uniform specific activity $(1.2 \mathrm{E}-08 \mathrm{Ci} / \mathrm{g})$ indicative of their origin from the well-mixed molten body; the glass, indicative of the excellent quality of the vitreous waste form, contained no smearable or transferrable activity. Thus, the overall environmental impact of the incident relative to spread of contamination, either airborne or solid fragments, was insignificant.

The fire damage and general thermal stress to the project's equipment were completely limited to the off-gas hood; all other off-gas processing and control equipment, data acquisition systems, and 
electrical transformation equipment were undamaged. Direct damage to hood components was estimated at around $\$ 500,000$ including the central baghouse filter unit, the material addition system, and various electrical lines and control and monitoring devices on the hood.

Although no personnel were in any of the heat-affected areas at the time of the melt expulsion incident, many regular tasks did require personnel to enter potentially dangerous areas on and around the off-gas hood. Procedures will be modified to minimize the need for personnel entry into dangerous areas or provide adequate protection during necessary tasks. Many data collection and process control tasks can be done remotely through small modifications to equipment. Other monitoring tasks will be automated to eliminate the need for personnel access. One task, the addition of electrode sections, will still require personnel access to the hood work platform. Personnel protective clothing for thermal stress will be required for this task.

The off-gas hood itself, in addition to repairs, will be modified to handle future melt expulsion events in a controlled manner. Venting techniques, possibly including hood lifting, will be designed to relieve pressure surges and deliver the off-gas to areas that will be restricted from personnel access. The minimal airborne contamination experienced allows for unfiltered releases during possible future incidents. Some areas of the hood will be insulated where equipment might still receive thermal stress. The fabric elements of the off-gas roughing filter, which in the present configuration are directly exposed to any expelled molten material, will be analyzed for protective techniques to prevent damage by splashes of molten glass.

The root cause of the melt expulsion incident was inadequate design for project operations. The melt expulsion scenario was clearly not considered very probable; thus, its potential effects were not addressed in either the equipment design or the project procedures. Although similar melt expulsions events had been experienced in 3 of the previous 70 large-scale ISV melts, previous incident investigations have implicated man-made subterranean structures (e.g., tanks, concrete barriers, drums), which were thought to constrict the normal flow and dissipation of off-gas around the growing molten body.

Off-gas from ISV melts is composed mostly of steam as soil moisture is distilled due to its proximity to the molten body. Pit 1 site characterization investigations eliminated the possibility of manmade structures like concrete floors/walls as well as buried objects like tanks or drums. However, pit 1 was constructed in 1951 by excavation to a strata of dense, unweathered rock which could have contributed to constrain off-gas (steam) movement around the melt body in the soil-filled pit during ISV. Although several corrective actions are planned to minimize the possibility of melt expulsion events in future ISV operations at ORNL pit 1 , the design basis for all future ISV operations must be a melt expulsion event similar in nature but probably larger in size than that experienced on April 21, 1996. Operating procedures must address this design basis to protect both personnel and equipment while also attempting to minimize the probability of its recurrence.

Several techniques have been identified to minimize the probability of future melt expulsions. First, groundwater within pit 1 must be drawn down well below the target depth for ISV treatment. Before the melt expulsion incident, the bottom of the pit 1 molten body was $\sim 10 \mathrm{ft}$ below the regularly monitored elevation of standing water in the pit within 20 lateral $\mathrm{ft}$ of the melt body. Although the movement of this water may have contributed to the melt expulsion, its presence indicates that all surrounding soil porosity was filled with water, thus, little unsaturated pore space was available for potential transmission of steam away from the melt body. Therefore, removing standing water around an ISV melt body would divert this potential hydrostatic constraint on steam movement from the heated zone. 
Second, flow-monitored and curved vent pipes will be considered for installation at several layers beneath the growing melt body to provide facile pathways to release steam into the off-gas hood without relying on the obviously unpredictable soil porosity. The use of straight vent pipes in the previous ISV test design resulted in significant submelt strata being inherently unaccessible to venting; lack of a credible vent pipe operational verification technique was also apparent in the present incident.

Third, pressures beneath the melt body need to be measured to ascertain when steam pressure approaches the lithostatic pressure of the melt body so that power to the melt can be attenuated to reduce the rate of steam generation. Submelt pressure measurement will be attempted using buried screened-end tubing connected to pressure transducers above ground. Submelt pressure measurement represents the only plausible method to predict potential melt expulsion in sufficient time to take action to prevent it.

Fourth, quality video monitoring of the melt surface activity will be attained in future ISV operations at pit 1. Previous melt expulsion incidents were sometimes preceded by smaller bubbling activity or unusual melt surface movements. The pit 1 ISV operations lost video monitoring capability due to fouling of windows, which resulted in extremely poor to entirely indistinct video images. 


\section{EVENT SUMMARY DESCRIPTION}

An old seepage pit, last used for the disposal of radioactive liquid waste in 1951, was being converted from its present condition of untreated contaminated residual soil into an improved glass waste form as part of an in situ vitrification (ISV) demonstration project. Approximately $2 \mathrm{MW}$ of electrical power was being supplied to the ground, and an estimated 216 tons [196 metric tons $(\mathrm{Mg})$ ] of molten soil, containing $2.43 \mathrm{Ci}$ of radioactivity of which more than $99 \%$ was ${ }^{137} \mathrm{Cs}$, was being processed at the time of the melt expulsion incident. The ISV melting operations had been occurring normally at the site since April 4, with several planned interruptions for equipment testing and sampling and had been in continuous normal operations for about $72 \mathrm{~h}$ immediately prior to this melt expulsion incident.

At about 6:12 p.m. EDT, Sunday, April 21, 1996, a significant melt expulsion incident occurred during field operations of an ISV project at Oak Ridge National Laboratory (ORNL). Apparently, a large expulsion of steam and molten glass occurred causing the overlying off-gas collection hood to displace vertically, releasing the hot pressurized steam (Fig. 1). No personnel were injured nor were any personnel contaminated as a result of this melt expulsion incident. However, within seconds of the hot gas and/or molten glass release, peripheral combustible equipment (electrical insulation, rubber hoses, fiberglass trays, etc.) on and around the off-gas hood caught fire due to the intense heat (Fig. 2). Emergency personnel were notified and were on site by $6: 15$ p.m. All electrical power to the ISV equipment was turned off at the emergency switch at the site. But fire-fighting actions were not recommended or taken due to the unknown potential for large steam releases from the still hot hood and surrounding equipment. The small smoldering fires were allowed to self-extinguish as the source of intense heat dissipated quickly.

Samples of air and smoke from within the site, taken during the residual fires, revealed no radioactive contamination other than natural radon, which emanates from any heated soil. However, later that evening, numerous pieces of radioactive glass were found on-site, apparently ejected from the ISV melt during the melt expulsion incident. As a precaution, the Melton Valley Access gate (Post 24) was closed to all traffic until more detailed surveys were completed. As a further precaution, site personnel present during the melt expulsion incident underwent whole body assays and urine analyses, which determined that no low-level contamination had occurred. It appears that radioactivity was well contained within the ISV glass and $0.13 \mu \mathrm{Ci}$ of ${ }^{137} \mathrm{Cs}$ was emitted to the air during the melt expulsion incident. This amount of activity, even if channeled to the nearest residence on the perimeter of the Oak Ridge Reservation, would not result in a measurable or detectable dose, i.e., about $0.02 \mu \mathrm{rem}$.

\section{MAJOR CONCERNS DURING AND AFTER THE MELT EXPULSION INCIDENT}

Major concerns for the ORNL ISV project raised by this melt expulsion incident break down into three categories: personnel safety, environmental contamination, and equipment damage. These are discussed by category although many concerns overlap categories. 


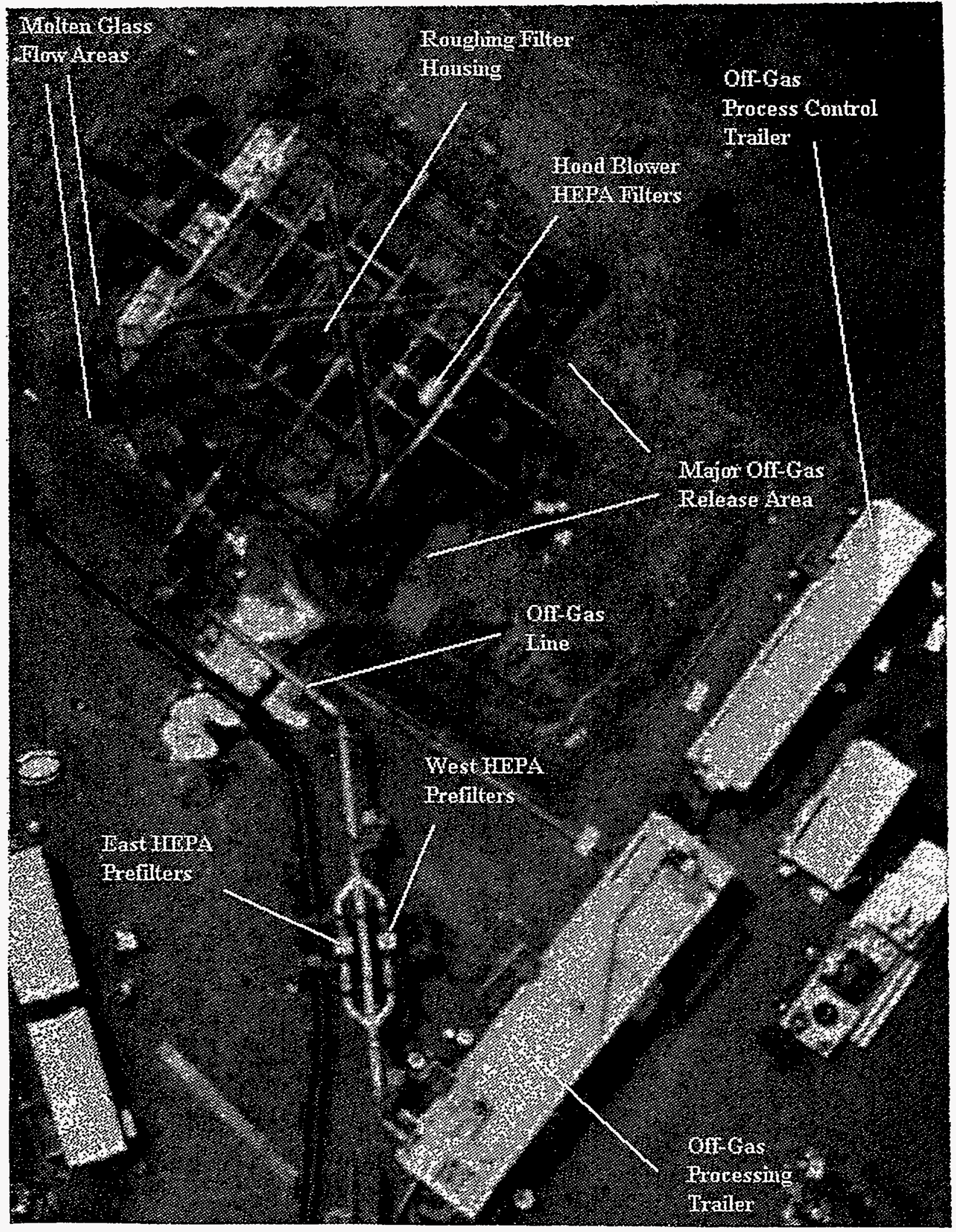

Fig. 1. Areal photograph of ORNL ISV site on April 22,1996, with notations showing locations of key equipment and pertinent incident areas. 

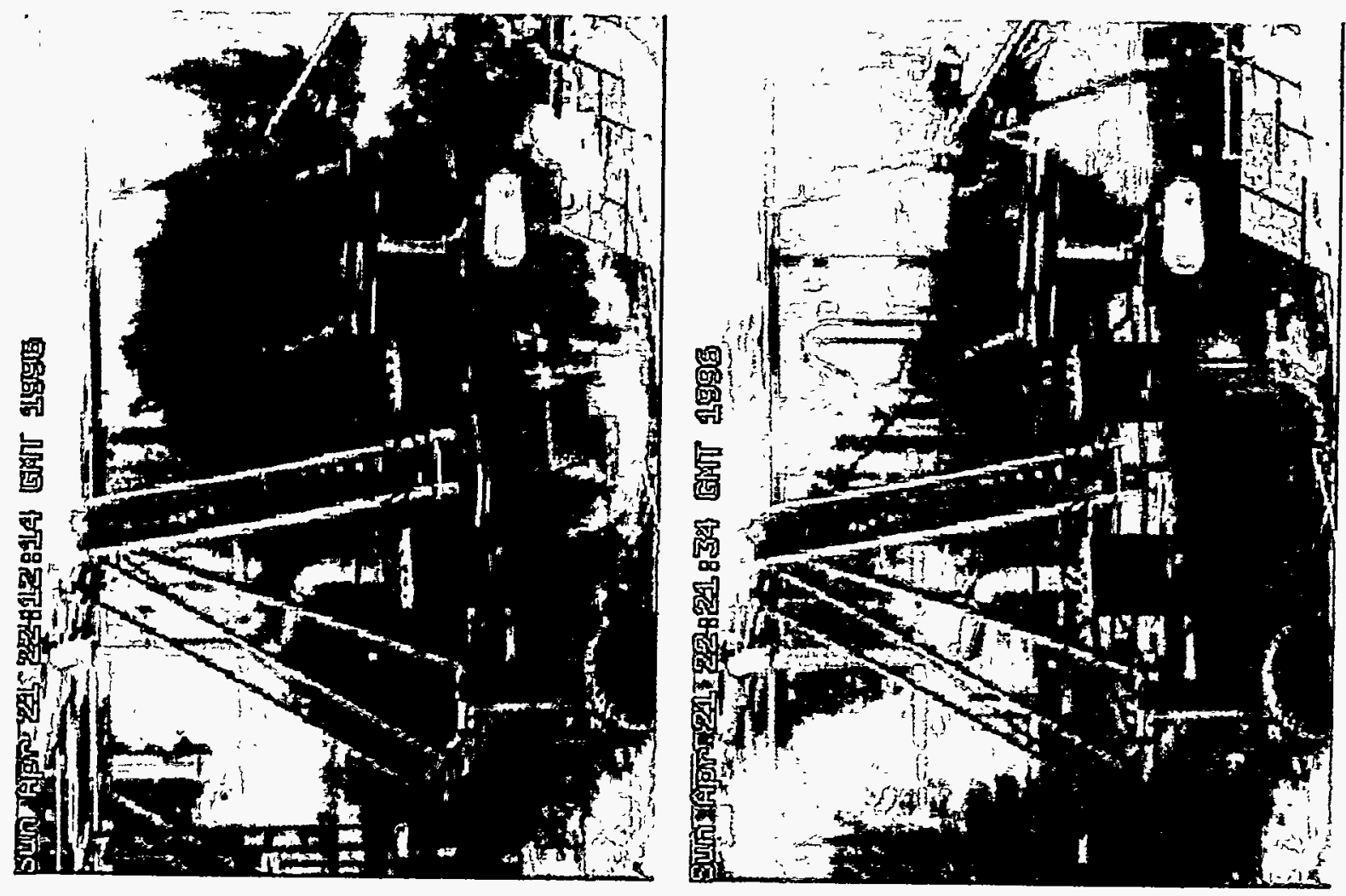

竞

㟧

I

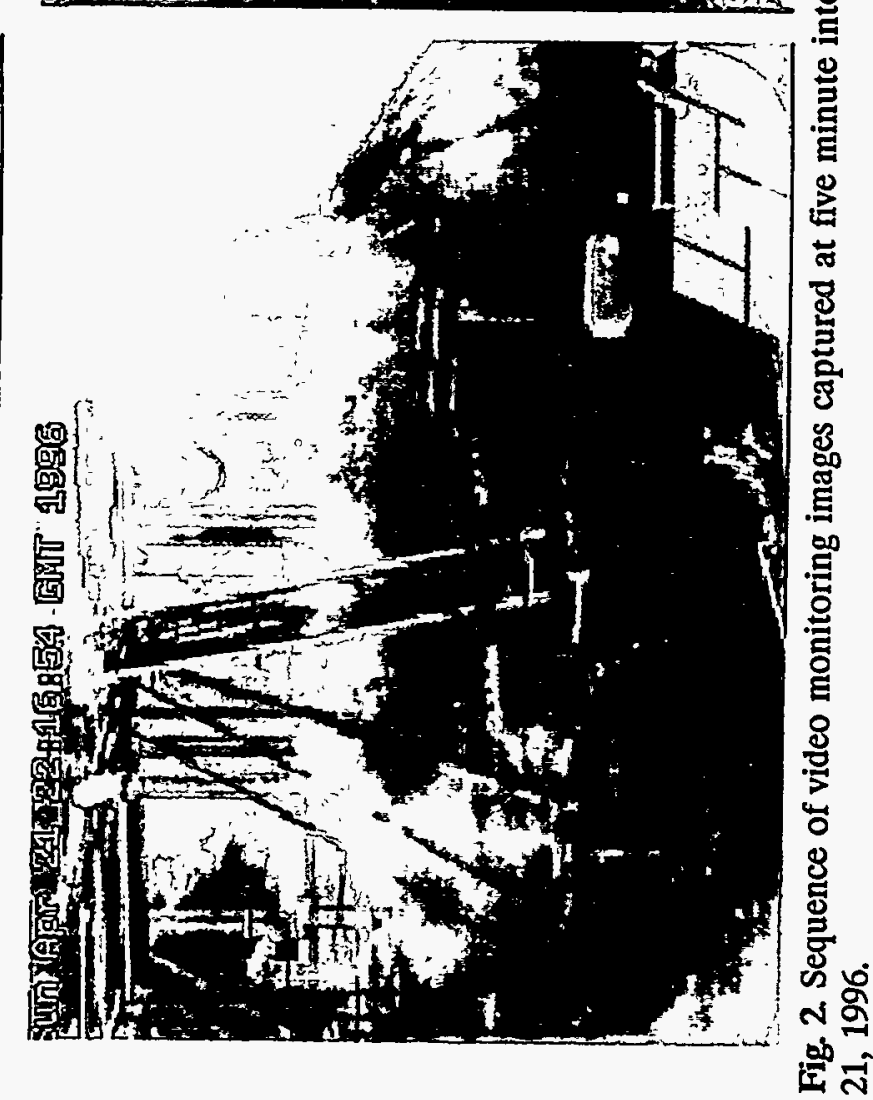




\subsection{PERSONNEL SAFETY}

During the ISV melt expulsion incident, four personnel were on site. The shift engineer and one operator were in the process control trailer monitoring process parameters during the melt expulsion incident. The second ISV operator was on a ladder outside preparing the off-gas sampling apparatus downstream of the west prefilter housing (Fig. 1) just to the northeast of the hood. A radiation protection technician was in the portable office/break building just east of the off-gas hood.

The outside ISV operator reported hearing a thud-like sound followed by a "ka-whoom." He reported seeing the north end of the off-gas hood raise about a foot from the ground and glowing hot gases issuing from the opening beneath the raised panels. The glowing jet of gases appeared to extend about $6 \mathrm{ft}$ to the north. The jetting lasted only a few seconds and the hood returned to the ground surface. He then climbed down the ladder and ran to the east of the site meeting the radiation protection technician who had exited on hearing the unusual sounds from the off-gas hood. Both these personnel proceeded to the small rise just to the east of the site on Melton Valley Access road. They both reported that the hood panels appeared to glow cherry-red when they looked back within the first minute of the melt expulsion incident.

The other ISV operator and the shift engineer reported observing a strong glow to the video image from the off-gas hood; the video image from the side camera was completely indistinguishable due to rapid accumulation of particles on its window through the hood wall. But it had been used as a kind of "optical pyrometer" over the previous several days, glowing more or less as the surface of the melt heated or cooled.

The shift engineer also reported some qualitative fluctuations in the visual displays of the process amperage and voltage about $10 \mathrm{~min}$ before the melt expulsion incident. Later, at the time of the expulsion, he reported feeling a slight tremor and hit the emergency electrode power switch (this engineer had been on duty during a previous ISV melt expulsion incident in Richland, Washington, in 1991 and recognized the melt expulsion incident's symptoms as identical to that previous event). He immediately called 911 for emergency assistance and then the ORNL project team leader, who was approximately a half-mile away in his office in ORNL Bldg. 1505.

While on the telephone to the 911 emergency responder, the shift engineer reported viewing the offgas through the window on the south side of the process control trailer. He also reported seeing the same jet of hot gas discharging directly towards him and the off-gas process control trailer. He moved away from the window expecting to feel a strong blast but did not. Subsequent viewing of the areas charred by the jet gas revealed that the steep 4-ft high embankment between the off-gas hood and control trailer deflected the hot gases up into the atmosphere rather than into the process control trailer. The ISV operator, who was in the process control trailer with the shift engineer at the time of the melt expulsion incident, left to check on the safety and location of the outside ISV operator and the radiation protection technician. All site personnel eventually met at the designated assembly point near the Melton Valley Access gate slightly after the arrival of emergency responders.

About this same time, both the ORNL project team leader and the Pacific Northwest National Laboratory (PNNL) project manager arrived on site from their offices in Bldg. 1505. Fire department personnel were preparing to fight the fires in peripheral combustible equipment (electrical cables, plastics, fiberglass walkways, etc.) on and around the off-gas hood. The ORNL project team leader cautioned them to wait until power was completely turned off at the site before spraying any water onto these small fires. He then proceeded to turn off power at the emergency switch on the site power pole and, following the startup of the emergency generator, proceeded to turn off the emergency generator. 
He met the shift engineer leaving the process control trailer on the way to the portable generator trailer. Upon returning to fire department personnel and consulting with the PNNL program manager, it was decided not to fight the small fires on the hood perimeter as a large amount of steam would likely be generated with unknown effects on possibly continuing or further release of radioactive off-gas. This consultation between project staff and emergency responders proceeded as planned in the project's Health and Safety Plan; both the Laboratory Shift Supervisor staff and Fire Department personnel had participated in site briefings and tours immediately prior to the start of ISV operations.

No personnel were injured during the melt expulsion incident because no personnel were in the danger zones on or immediately around the hood. However, such a scenario of off-gas release was not addressed in personnel safety planning for this project; had project personnel been performing any of several routine tasks on or around the off-gas hood, they would have been at considerable risk of injury. Previous ISV off-gas pressurization and melt expulsion incidents had all involved buried structures in the soil subsurface, which were believed to constrain off-gas flow away from and around the melt bodies. In the present ISV operations, no man-made structures were contained in ORNL pit 1, thus, it was believed that such a off-gas constraint scenario would not be possible there.

As an additional precaution for off-gas pressurization and, thus, a tacit admission that it might occur, vent pipes were installed at various depths and angles beneath the predicted melt geometries at various times; these pipes were to provide reduced-resistance conduit for ISV off-gas to the collection hood rather than relying completely on the natural porosity of the soil in pit 1 . Whether these vent pipes functioned or not during the ISV melt is presently unknown as the visual inspection technique using the video image of the interior of the hood was not available.

It should also be pointed out that the region of the melt near contact with the denser undisturbed rock at the pit 1 bottom could not be vented via such pipes, which could not be driven into this dense material. Thus, although project planning activities weighted heavily the hazards of hot surfaces, high voltage, and radioactive contamination associated with ISV, little attention was placed on the perceived unlikely event of off-gas pressurization and its associated risks.

All four personnel on-site during the uncontrolled release of ISV off-gas were monitored for contamination of skin and clothing before leaving the site; none was detected. The next day, all four were subjected to whole-body and lung assays for any internal contamination that may have been inhaled or ingested during the melt expulsion incident. All four personnel also submitted urine samples over the next two days in a further effort to identify any possible contamination. All assays exhibited no detectable radioactive contamination. Obviously, this is not surprising given subsequent air monitoring data and the fact that no project personnel were directly in the off-gas release from the hood. Considering the unknown nature of contaminant release during and immediately following the melt expulsion incident, such personnel monitoring was an extremely prudent precaution.

\subsection{ENVIRONMENTAL CONTAMINATION}

Environmental contamination was of concern after the melt expulsion incident in three different areas: the uncontrolled release of radioactivity to the air, the distribution of radioactively contaminated glass within and outside the hood, and the planned/expected contamination of off-gas processing equipment. Perhaps the most critical information, which had to be reconstructed after the melt expulsion incident, was the amount of radioactivity that may have escaped from the off-gas hood during the 
uncontrolled release period when it was open to the atmosphere. Such a calculation is critical for future ISV operations as it will allow for design of safe radiological operations during a potential recurrence of such an uncontrolled release.

\subsubsection{Activity of ${ }^{137} \mathrm{Cs}$ in Samples of Glass Expelled From ISV Hood}

Samples of glass were collected on the day after the melt expulsion incident from around the ISV off-gas hood on the south and southeast sides. In addition, on April 26, 1996, two samples of glass, dangling from roughing filter elements, were obtained during sampling of these filter fabrics. Using $\mathrm{NaI}$ gamma spectroscopy on crushed specimens, the activity of ${ }^{137} \mathrm{Cs}$ was assayed; other radionuclides $\left({ }^{90} \mathrm{Sr}\right.$, ${ }^{238} \mathrm{U}$, and ${ }^{239} \mathrm{Pu}$ ) have not been assayed (but will be at a later date as part of the evaluation of the overall ISV project) because they do not have sufficient volatility from ISV melts to be detected in ISV off-gas. The average activity for all samples of the ISV product was $1.22 \mathrm{E}-08 \mathrm{Ci} / \mathrm{g}$ and exhibited little variation between expelled and internally splattered glass.

Previous product samples, taken directly from the melt after the operational acceptance test (OAT) phase on April 19, 1996, averaged $2500 \mathrm{dpm} / \mathrm{g}$ or $1.129 \mathrm{E}-09 \mathrm{Ci} / \mathrm{g}$. At the time of the melt expulsion incident, molten material being processed amounted to about an order-of-magnitude more radioactivity than during the OAT. With a melt size of $196 \mathrm{Mg}$ at the time of the melt expulsion incident, the total inventory in the melted mass would be $2.43 \mathrm{Ci}$ of ${ }^{137} \mathrm{Cs}$.

It was also discovered that the samples of hair-like fiberglass, taken at some distance from the hood, were approximately the same specific activity of ${ }^{137} \mathrm{Cs}$ as the bulk glass that flowed from under the hood or was splattered onto the roughing filter. Thus, the thin threads of glass around the site must also have originated from the melt. Observations of the molten glass flow at the southeast corner revealed many fiber strands frozen in the process of formation; apparently, the ISV off-gas that escaped through the narrow gap between the hood foot and the ground surface was of sufficient velocity to entrain glass, which rapidly cooled to solid fibers as it traveled a short distance into the cooler surrounding air.

\subsubsection{Off-Gas System Contamination}

Major components of the ISV off-gas system handling equipment were sampled to determine the distribution of ${ }^{137} \mathrm{Cs}$ subsequent to the melt expulsion. By normalizing the distribution of ${ }^{137} \mathrm{Cs}$ relative to the entire inventory being processed by the molten body, the perspective of contaminant distribution can be gleaned for any future processing inventory and the environmental consequences of possible future incidences assessed. Major off-gas system components include 1) the hood's roughing filter at the central off-gas intake, 2) the two banks of high efficiency particulate air (HEPA) prefilters in the off-gas line between the hood and the off-gas processing trailer, 3) the HEPA filter bank for the hood's backup blower, 4) the off-gas scrub system solutions, and 5) various hood panel and pipe internal surfaces onto which off-gas particulate contamination may have been deposited.

The HEPA prefilters included the bank in use at the time of the melt expulsion incident as well as the bank that had been in use for several days prior to the melt expulsion incident; the HEPA prefilters had been changed eight times over the pit 1 melting operations whenever particulate buildup was sufficient to result in a differential pressure greater than about $7 \mathrm{in}$. water column. The HEPA filters in use during the incident were significantly deformed, but otherwise apparently functional, due to a pressure surge through the off-gas line. The HEPA filters on the hood backup blower were sampled because, although the hood blower was not on during or after the melt expulsion incident, it would have received a pressure surge of off-gas and may have contained some contamination. 
Results of the distribution of ${ }^{137} \mathrm{Cs}$ are depicted in Fig. 3. Most notably, $99.9981 \%$ of the ${ }^{137} \mathrm{Cs}$ was retained in the ISV molten body subsequent to the melt expulsion incident. Of the $0.0019 \%$ of the ${ }^{137} \mathrm{Cs}$ activity that was released into the process off-gas, most was retained on the hood's roughing filter. Of the fraction that passed the roughing filter, all was retained on the HEPA prefilters as no ${ }^{137} \mathrm{Cs}$ was detected in the off-gas scrub system solutions. Measurable activity, found on the HEPA prefilters switched out of the off-gas flow about two days prior to the melt expulsion incident, indicates that ${ }^{137} \mathrm{Cs}$ was being incorporated into the growing ISV molten mass for several days before the melt expulsion incident. The HEPA filters on the hood's off-gas backup blower also contained a significant fraction of the total off-gas inventory. Field surveys of the smear samples from various hood panels and the off-gas pipes did not reveal detectable activity; these samples will be assayed in the low-background laboratory environment for quantification of their low-level activity. Their contribution to the total off-gas inventory and distribution would be trivial compared to the various filter samples, which yielded readily detectable activities with field survey instruments and during short $(10 \mathrm{~min})$ counting intervals in the lowbackground laboratory environment.

\subsubsection{Off-Gas Monitoring and Sampling}

Samples of the various filters and tapes from off-gas samplers were assayed for ${ }^{137} \mathrm{Cs}$ activity for the intervals immediately before, during, and after the off-gas release melt expulsion incident. Of particular interest was the Graseby-Andersen paper tape off-gas sampler that pulled off-gas from the intake of the roughing filter; this sampler would yield the best representative sample of the off-gas released during the uncontained interval of hood pressurization. Although this particular sampler had been malfunctioning frequently prior to the melt expulsion incident due to off-gas moisture condensing and causing its paper tape to fall apart regularly, the sampler was functioning correctly and its performance verified during a regular field check about $80 \mathrm{~min}$ before the melt expulsion incident. It is unknown exactly how long the sampler was withdrawing an off-gas sample when the electrical power was shut off to the off-gas hood at around 6:30 p.m., within $20 \mathrm{~min}$ of the start of the melt expulsion incident.

A total of $49 \mathrm{dpm}$ of ${ }^{137} \mathrm{Cs}$ were detected on the segment of the paper tape in operation at the time of the melt expulsion incident. Assuming the sample was collected over the entire 20-min pre-set sampling interval, the off-gas activity concentration of ${ }^{137} \mathrm{Cs}$ was $1.229 \mathrm{dpm} / \mathrm{L}$ of gas. Any pressure surge into the sampling line during the melt expulsion incident would result in a lower activity concentration; hence, the reported activity concentration is conservative, i.e., tending towards a probable higher number. This activity concentration will be used in combination with an estimate of off-gas volume released during the period when the hood was off the ground surface and pressurized.

The other functional off-gas sampler was located immediately upstream of the HEPA prefilters and functioned to sample off-gas that had passed through the roughing filter. This sampler was also functioning at the time of the melt expulsion incident; it exhibited low detectable activities of ${ }^{137} \mathrm{Cs}$, which did not differ from those before the melt expulsion. This lack of difference in activity points to the continued functioning of the roughing filter during the melt expulsion incident.

\subsubsection{Ambient Air Monitoring}

Immediately before and during the pressurization and melt expulsion incident, three ambient air samplers/monitors were functioning. A Graseby-Andersen paper tape sampler, located approximately $30 \mathrm{ft}$ to the southeast of the hood during the melt expulsion incident, was powered from an electrical outlet at the portable storage building. The two portable storage/office buildings drew their electrical power directly from the supply line to the east and, thus, were not interrupted during the emergency 


\section{Distribution of ${ }^{137} \mathrm{Cs}$ \\ Following ISV "Burp" of April 21, 1996}

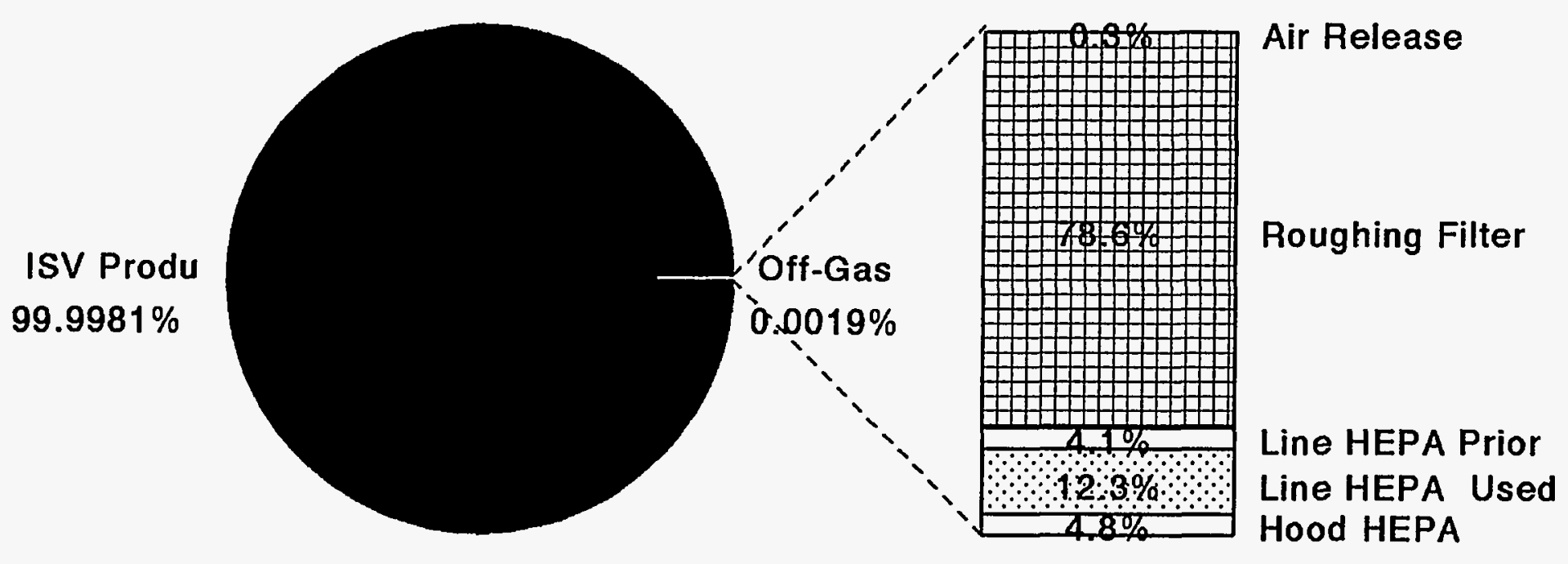

Total $-2.43 \mathrm{Ci} \quad$ Off-Gas Total $-0.0000451 \mathrm{Ci}$

Fig. 3. Distribution of ${ }^{137} \mathrm{Cs}$ in ISV off-gas and equipment following the incident of April 21. 1996. 
power shutdown shortly after the melt expulsion incident. Activity on these samples could not be distinguished from background before, during, or after the melt expulsion incident.

The other two ambient air samplers were AMS-4s that contained filters which, per procedure, were replaced manually at intervals of approximately one day. One sampler was positioned inside the off-gas processing trailer to monitor the operators' breathing air; hence, it was shielded from any contact with outside air during the melt expulsion incident. No activity was detected on this monitor. The other AMS4 had been used as an off-gas stack monitor for most of the melting operations but had been switched to an ambient air monitor after the OAT because of continued moisture condensation problems when sampling the off-gas stack. It was on the north side of the off-gas processing trailer approximately 70 $\mathrm{ft}$ north of the northeast corner of the off-gas hood. It appears unlikely that this sampler was in the influence of any of the off-gas release, which was centered more to the west. Regardless, no detectable activity of ${ }^{137} \mathrm{Cs}$ was observed on the last filter sample collected from this monitor.

In general, winds at the time of the melt expulsion incident were from the southwest although velocities were low and variable. On his arrival, the project team leader noticed that the smoke cloud from the subsequent hood perimeter fires had risen quite high before slowly moving to the northeast of the site. Thus, none of the ambient air monitors or samplers were in a position for optimal interception of any escaping off-gas plume. Thus, it is not surprising that no detectable activity was found on any of these filter samples.

\subsubsection{Uncontrolled Air Release Estimate}

To estimate the volume of off-gas released during the period of unconfined and pressurized hood, the universal gas law was used along with the off-gas hood's confined volume, estimated temperatures, and confining pressures under pre-event, maximal event, and post-event conditions. From the activity of ${ }^{137} \mathrm{Cs}$ collected on the Graseby-Anderson paper tape sample of the hood off-gas for the volume sampled during the event, an activity concentration in the off-gas was calculated as described above; using this measured concentration of activity and the estimated total volume of off-gas released, the total release of ${ }^{137} \mathrm{Cs}$ activity was calculated.

The measured concentration of ${ }^{137} \mathrm{Cs}$ activity in the off-gas was $1.229 \mathrm{dpm} / \mathrm{L}$. This activity was measured on the last spot on the Graseby-Andersen tape sampler of off-gas within the hood, and the concentration was calculated from the sampler settings of a 20-min sampling interval and a flow rate of $2 \mathrm{~L} / \mathrm{min}$. The estimate of the volume of pressurized off-gas, which was released during the brief interval of hood lifting, was $230,000 \mathrm{~L}$ at standard temperature and pressure. This would yield an uncontrolled release of $1.229 \times 230,000=282,670 \mathrm{dpm}$ or $1.27 \mathrm{E}-07 \mathrm{Ci}$ of ${ }^{137} \mathrm{Cs}$.

\subsubsection{Distribution and Dispersion of ISV Glass}

\subsubsection{Glass flow Eutside hood}

Major amounts of the expelled ISV glass product flowed outside the hood panels, but almost all of it was confined to the southeastern corner of the hood (Fig. 4).

\subsubsection{Morphology of expelled glass particles}

Two types of glass particles were observed around the off-gas hood unconnected with the bulk flow of glass under the hood panels. These were generally in the form of irregular globs (Fig. 6), which usually occurred within $20 \mathrm{ft}$ of the hood, and fibers of glass, some quite thin (Fig. 7), which occurred 


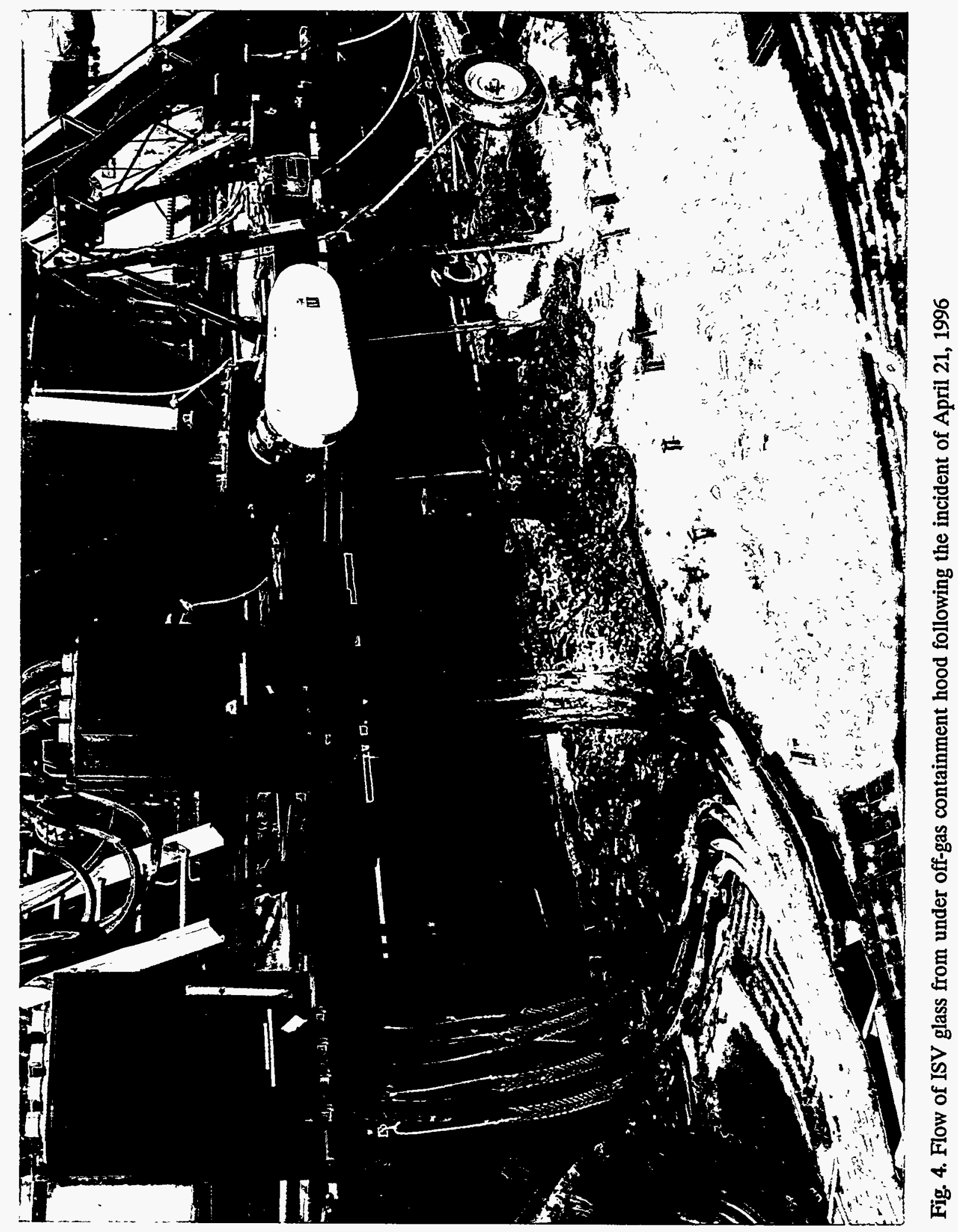




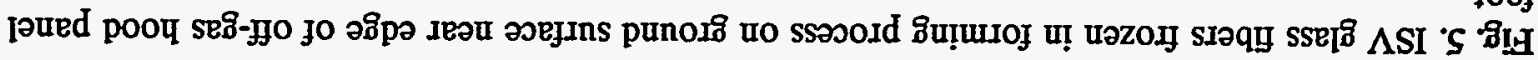

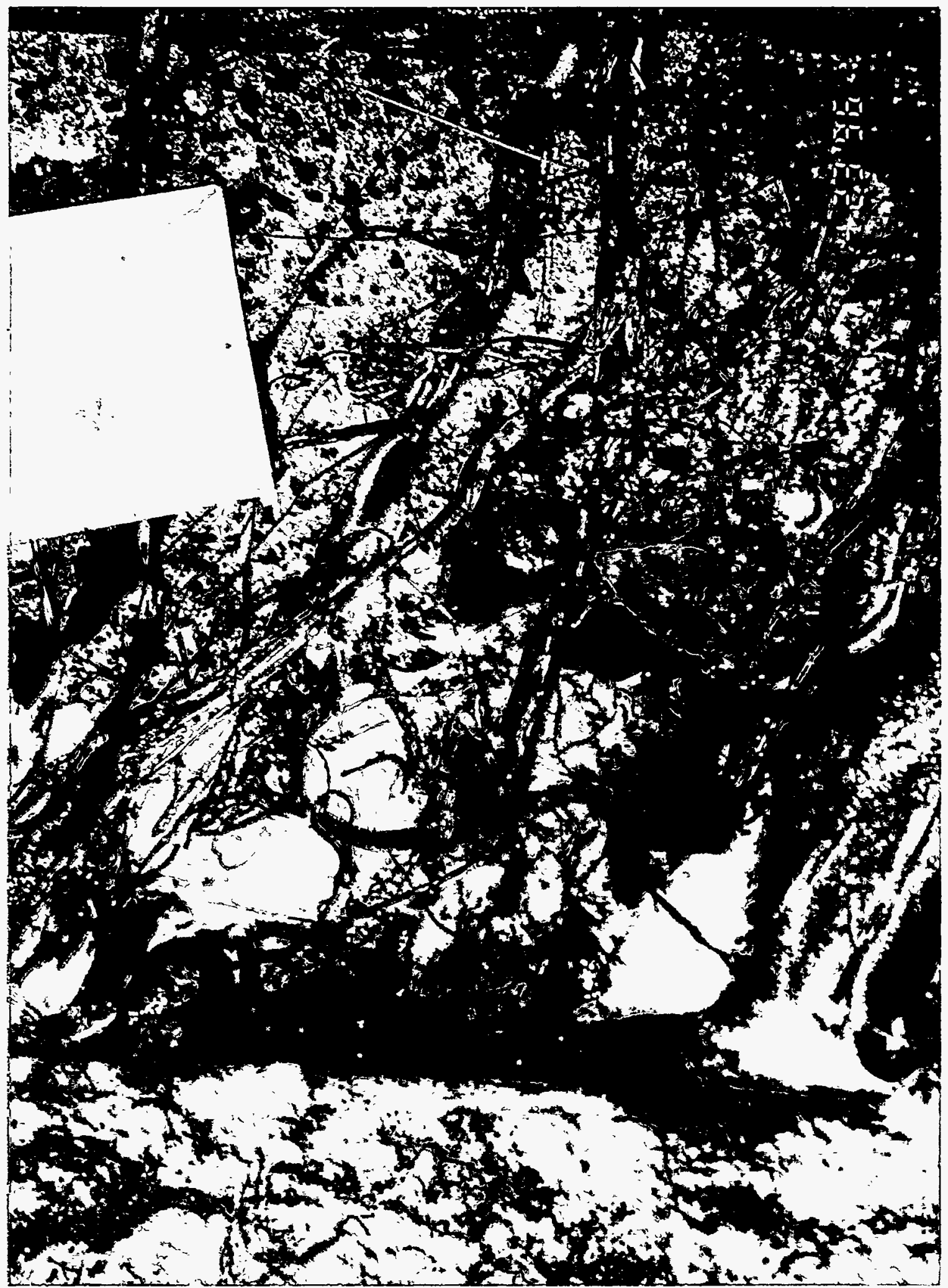




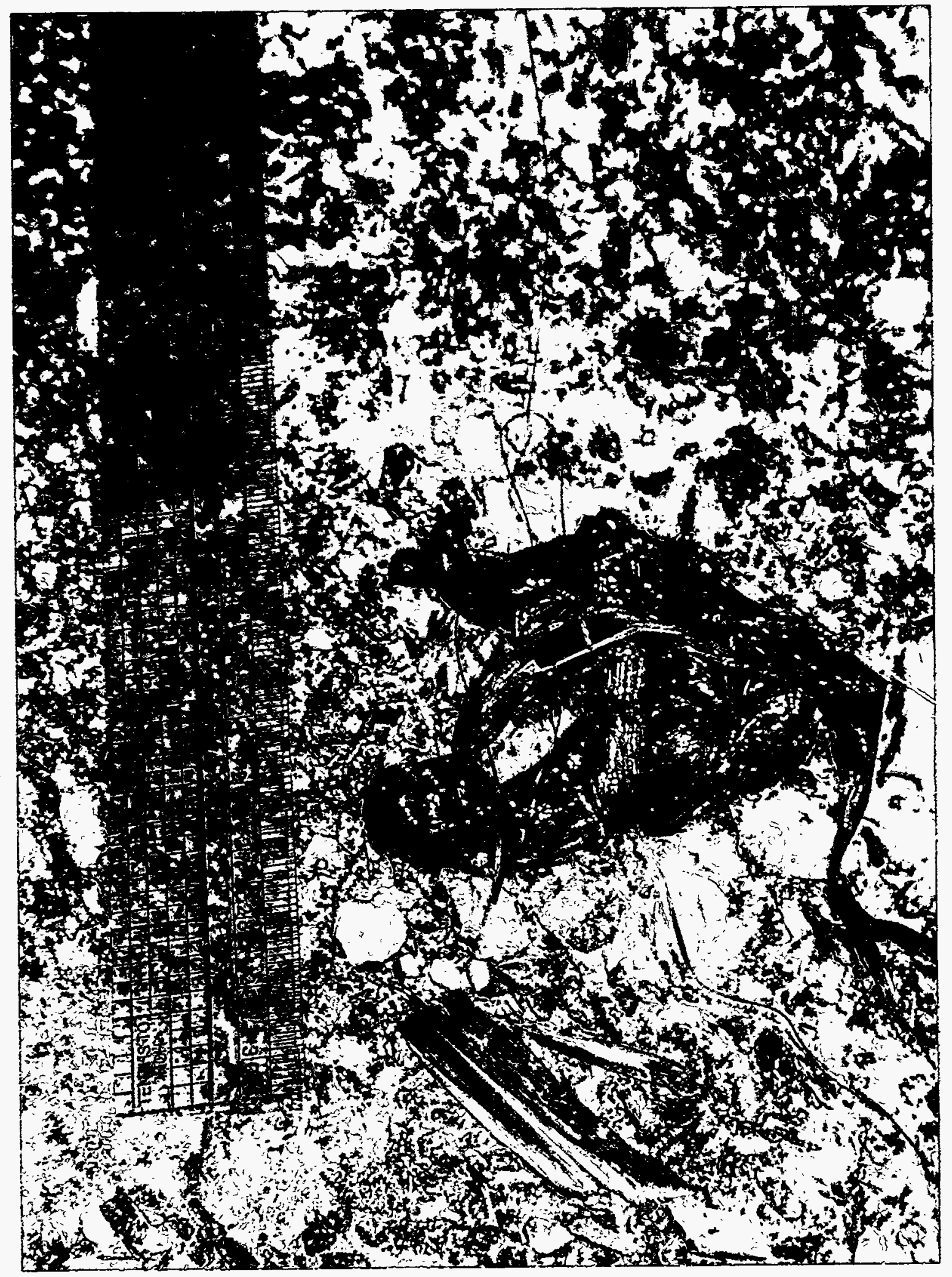

Fig. 6. Expelled ISV glass glob on ground surface just to east of off-gas hood 


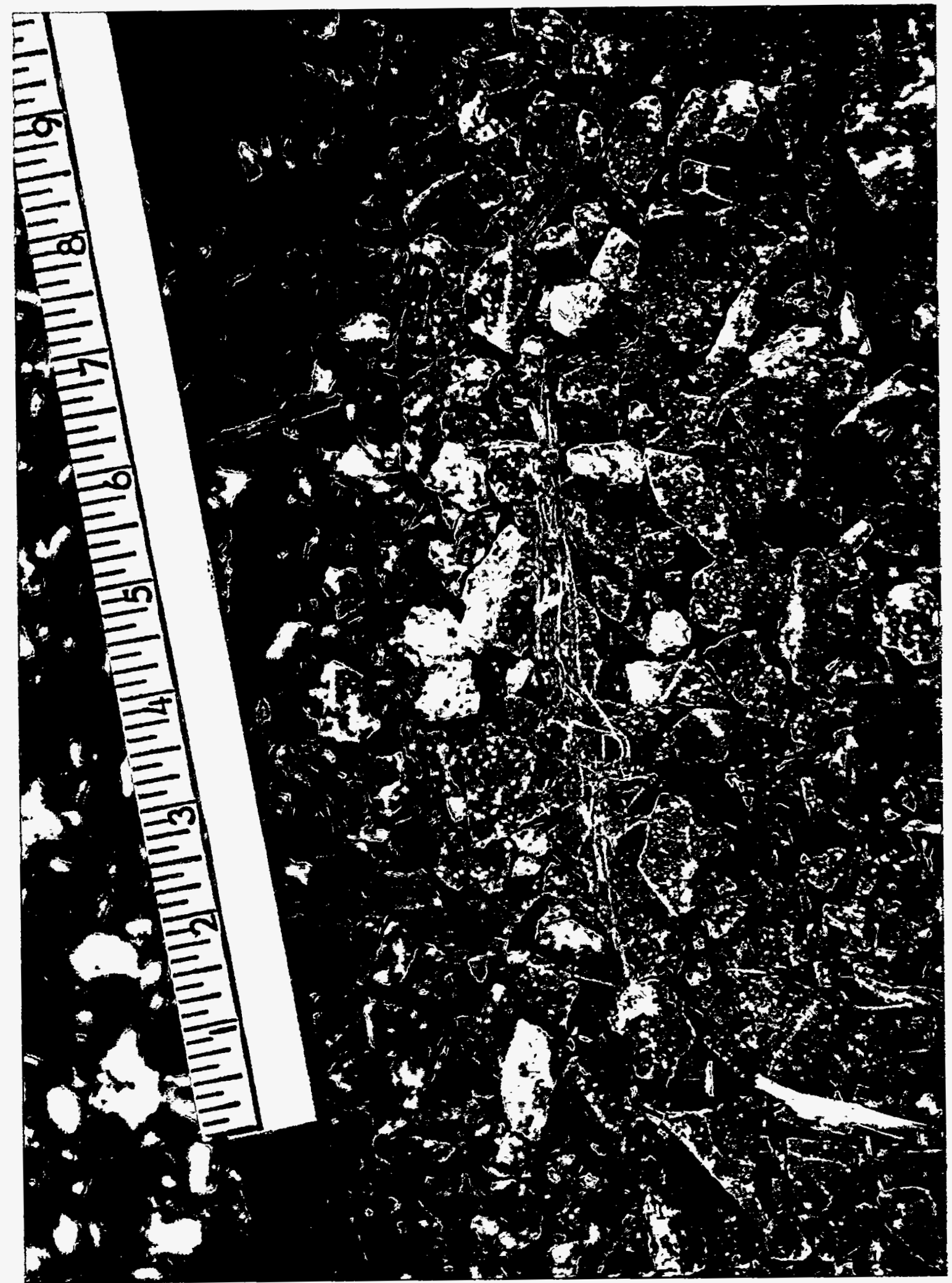

Fig. 7. Hair-like form of ISV glass expelled approximately 20 feet east of off-gas hood during incident of April 21, 1996 
up to $300 \mathrm{ft}$ away from the hood and must have had some aerodynamic attributes to be carried that far. Both of these types of expelled glass appear to have been formed by high velocity off-gas jetting over a molten surface from just underneath the hood panel foot. Actual glass fibers and globs, in the process of forming, when pressurizing and lifting of the hood had ceased, can be seen on the south side of the off-gas hood (Fig. 5).

\subsubsection{Distribution of expelled glass}

The distribution of expelled glass within and around the hood is summarized in Fig. 8. This distribution estimate was based on visual examination as personnel entry into the hood is presently precluded. In the southwest quadrant, the glass flow extends approximately $10 \mathrm{ft}$ from the starter pit and appears to be about 2 in. thick. Most of the surface immediately in front of the southwest comer hood panel is only sparsely scattered with glass. The Cerwool blanket, which was laid over the entire ground surface inside the hood prior to start of ISV operations, was still visible.

The entire southeast quadrant appears to be glass-covered. The once "level" ground surface under the hood appears to be depressed by about 4-5 in. immediately south of the starter pit. This depression extends out from the starter pit a distance of approximately $10 \mathrm{ft}$. From the northeast corner hood opening, the glass flow appears to be $10-15 \mathrm{ft}$ out from the starter pit and nominally $2 \mathrm{in}$. thick. There are several hundred 2- to 3-in.-tall glass stalagmites/spikes on the ground surface north of the starter pit.

\subsection{EQUIPMENT DAMAGE}

When the melt expulsion incident occurred, the hood was observed to have broken its seal with the ground and lifted around the base a maximum of 12 in., at least on the one side observed during the event. As a result, on all sides the ground seal is broken, and the base of the hood panels remains lifted up about 6 in above its nominal 4 in. depth of burial in the ground. On the north end, a blast of hot gas was observed to be emitted, which resulted in most of the combustible matter in its path being burned up. This included several cardboard boxes (containing noncombustible materials) and vegetation on the graded slope to the present pit surface.

A section of fiberglass grating had been placed on the ground under the catwalk on the hood to act as a walkway across the muddy soil surface of the pit. When this grating burned, it contributed to much of the damage to hood equipment on the north side. Damage includes the control panel for the hydraulic system and all hood instrumentation (wires, valedines, magnehelic, heat flux pad, etc.).

Other damage on the north side includes the Remtron antenna signal panel (apparent short in the signal wires), the window view port (glass is broken, window shield will not rotate-housing is warped), and the light and electrical insulation (melted). The paint on the drive panel is burned but there is no obvious damage to the inside electrical equipment; further troubleshooting is required to confirm the functional status of the drive system.

\subsubsection{Damage on Hood Perimeter}

On the east side, there was a pile of gravel covering about the north half of the area between the hood and the graded slope of the pit. The gravel pile extended down to within about $1 \mathrm{ft}$ of the base of the hood and was under all the electrical panels on the north end of the east side. There is melt flow out 


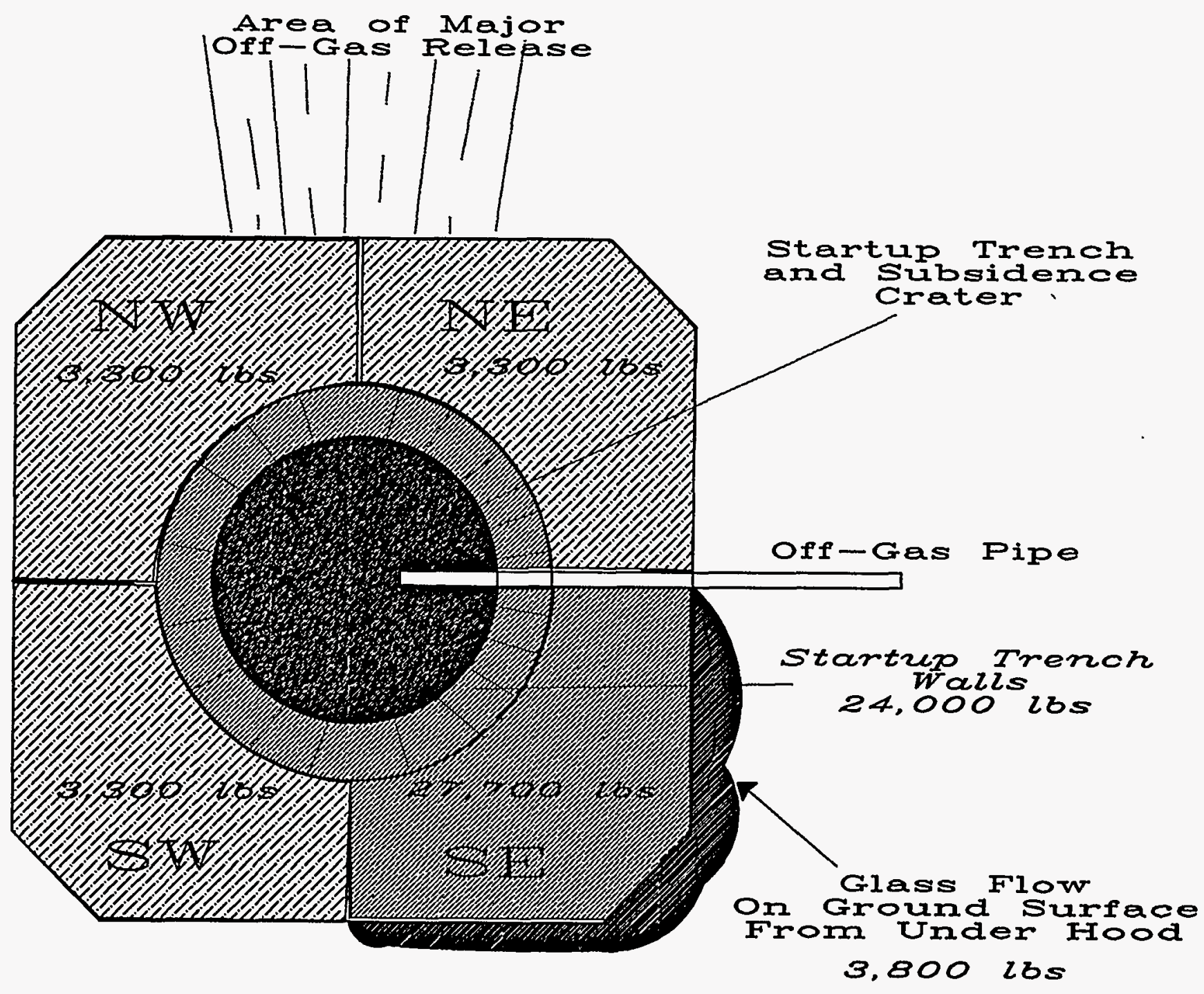

Fig. 8. Estimation of distribution of ISV expelled glass within and around off-gas collection hood after April 21, 1996 incident 
from under the hood on the south half of the east side. It extends out from the edge of the hood panels about 3 to $5 \mathrm{ft}$ and is about 4 to $6 \mathrm{in}$. thick. The insulation on the high voltage cables is burned (about the last $10 \mathrm{ft}$ of each of the 8 cables) as they run into the junction boxes.

The material addition system (MAS) pneumatic lines and controls were melted. The wheel on the feed conveyor toward the hood was burned. The support leg to the MAS hopper and the east leg of the southeast landing gear jack are sitting in glass and appear warped, and the gear box appears to have been adversely affected by the heat. These mechanisms need to be repaired or replaced. The paint on the backs of all electrical panels have been scorched, but the interiors of most appear to be unaffected except for the roughing filter control panel and the hoist remote control panel. All electrical wires running to the hood system appear to be unaffected except the hoist remote control cable and any instrumentation wiring adjacent to the hood panels in the area. The condition of the window view port on the east side is similar to that of the north window view port.

Inside the roughing filter control panel, the plastic tubing for pressure monitoring is melted and the bulk of wires that were resting on the bottom of the panel are melted, shorting the wires to ground. They can be easily repaired. The blow back control board does not appear to be damaged but will require further troubleshooting. The hoist remote control cable outer insulation is melted about 8 to $10 \mathrm{ft}$ from the junction box. It can be cut off and reconnected to the junction box. All hoist control cable (yellow vinyl) insulation routing from the junction box to the hoists is melted and will need to be replaced. The condition of the 480 - to $208 / 120$-volt transformer is unknown and will need to be inspected, but it appears to be in fair condition.

On the south side, melt flowed out of the east two-thirds of the hood; it extends 1 to $2 \mathrm{ft}$ and is about 4 to 6 in. thick. Fiberglass grating in the area was burned but did not cause damage similar to that observed on the north side. All hydraulic and pneumatic rubber hoses in the southeast corner are heat affected and will need to be replaced.

The inner tire on the southeast travel system has some charred tread and should probably be replaced. The sidewall appears to be in good condition, but since this is the most heat-affected tire, it should at least be removed and the tube and inside of the tire examined. If this tire appears to be in good condition, the others should be as well. The window viewport and light are in the same condition as the others. The MAS control panel appears to be heat affected. There are no shorts to ground in the supply power wiring, but all the controls and fuses appear damaged. The push buttons and switches appear to function except that the lenses are melted. The fiberglass housing for the Graseby-Andersen tape sampler is slightly heat affected but not scorched and could be reused. The tape sampler itself and radiation monitor need additional trouble shooting.

On the west side, there were no adverse thermal effects, and all the equipment appears to be in good condition (however, the west side is the side with the fewest components). The compressor, inlet air control valve, and camera control junction box all seem to be okay. The condition of the camera on the west window view port needs to be further evaluated.

\subsubsection{Damage on Hood Work Platform}

Most of the combustible items on the work platform were heat-affected. The hood blower over the grating that burned on the north side is slightly scorched. The wiring was pulled from its connection to the hood structure and reconnected (to pull vacuum on the hood during observations inside the panels) and works well. In fact, the wiring that was pulled from the conduit running along the north side of the hood structure appears unaffected (good news with regard to the wiring contained in conduit in general). 
All of the internal water spray pressure suppression system electrical controls are melted and would need to be replaced if the system is to be used again; however, replacement of this system has been deemed unnecessary as the proposed external water spray suppression system will more than adequately protect hood equipment. All of the hoist control cable (yellow vinyl) insulation needs to be replaced because the vinyl is melted and some of the twist lock plugs are damaged. One local hoist controller is melted and needs to be replaced. All of the nylon in the clamps were affected by the heat; some are completely burned. All sections need to be replaced and the clamps repainted. This could be an opportunity to improve the design and operation of the clamp (which was heavy and very awkward to handle). About 12 of the 16 electrode cables are heat affected at the bottom of the festoon loop (the four western-most cables were unaffected); they will need to be cut off and the lugs will need to be recrimped. There should be enough cable slack to not have to replace or even extend the cable with splice kits. Most of the grating has burned and peeling paint and should be repainted.

The roughing filter housing was highly damaged by the heat and somewhat warped. It was initially thought that it could be reworked in place so that the lids will fit properly; but, detailed examination revealed the need for a new housing top section. All bags and hardware (clamps, gaskets, etc.) will need to be replaced. The cages appear to be bent somewhat and will be replaced. Railing around the work platform was made of steel cable with plastic cover which has melted in some places. It may be possible to clean this railing and leave it uncoated or just paint it; otherwise, the cable rail will have to be replaced. The phenolic insulators and the phenolic and Nextel electrode seals on the electrode cradle are scorched and need to be replaced.

\subsubsection{Damage Cost Estimate}

Estimates for repair of hood damage range around $\$ 500,000$ although the actual cost will depend on how much functional damage to electrical equipment is finally determined. Presently, electrical power to the hood has been reestablished and systematic testing of circuits, breakers, switches, lights, motors, and control and instrument circuits has been completed. The cost for replacing each damaged component has been determined, but whether actual replacement or repair is necessary is not presently known. However, a systematic testing of the electrical systems will be the only method to firm up repair estimates and schedules.

\section{PROPERTIES OF MELTED SOIL PRESENT DURING THE MELT EXPULSION INCIDENT}

Three somewhat independent methods are available to estimate the mass of glass in the ISV melt body when the incident occurred. Melt mass estimation is important to 1) perform a process assessment using a mass balance to describe the distribution of contaminants, 2) estimate the fraction of pit 1 already treated, and 3) plan the additional ISV melts required to complete treatment of all source contamination.

Melt mass was estimated from 1) determining the amount of electrical energy applied to the melt assuming certain melting efficiencies, 2) determining the size of the melted or solidified body and assumptions about the product density and 3) measuring the final concentrations of the conservative tracers in the product and dividing this into their known additions to the soil. The best estimate of the mass of ISV product was $196 \mathrm{Mg}$ (216 tons) based on the rare earth dilution method. The final estimate of melt size and shape is depicted in Fig. 9. 


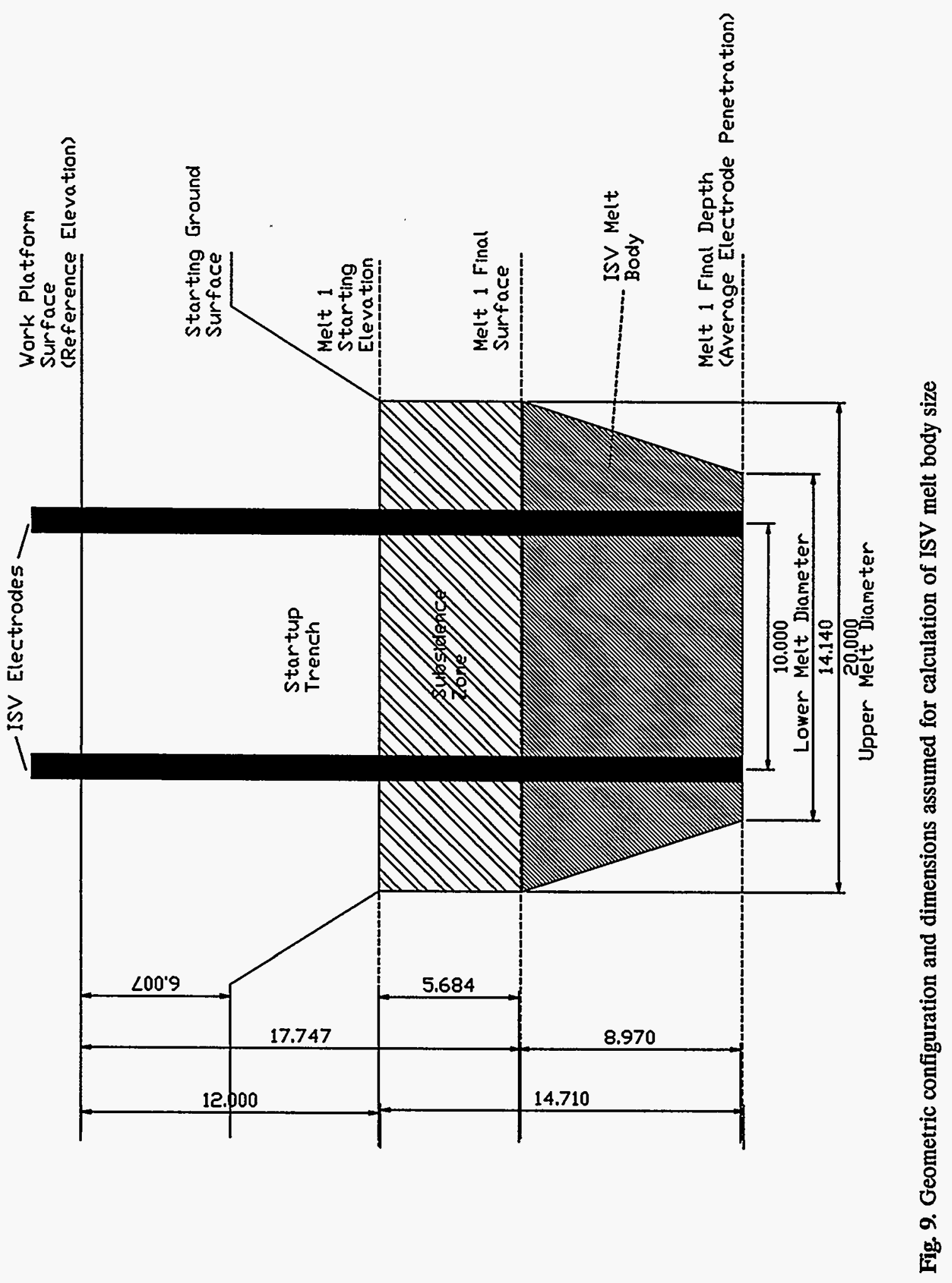


Two samples each of the expelled glass after the melt expulsion incident and the ISV product sampled after the OAT were pulverized and dissolved using the $\mathrm{LiBO}_{2}-\mathrm{HNO}_{3}$ technique described in the Quality Assurance Project Plan. The elemental composition of the glass (Table 1) will determine the ISV operating temperature. Although the compositions of the ISV glass were similar after the OAT and after the melt expulsion incident, significant minor differences are apparent. Calcium increased between the OAT and final melt due to addition of limestone with the MAS. The sodium content decreased between the OAT and final composition due to continued dilution of the initial charge of sodium provided in the feldspar starter sand.

Table 1. Elemental composition of ISV product at ORNL pit 1 after the Operational Acceptance Test (OAT) and the melt expulsion incident

\begin{tabular}{lll}
\hline Major component oxide & Melt 1 glass (\%) & OAT glass (\%) \\
\hline $\mathrm{Al}_{2} \mathrm{O}_{3}$ & 19.8 & 20.6 \\
$\mathrm{CaO}$ & 2.9 & 2.5 \\
$\mathrm{Fe}_{2} \mathrm{O}_{3}$ & 6.5 & 6.7 \\
$\mathrm{~K}_{2} \mathrm{O}$ & 2.0 & 2.0 \\
$\mathrm{MgO}$ & 1.6 & 1.5 \\
$\mathrm{MnO}_{2}$ & 0.06 & 0.06 \\
$\mathrm{Na}_{2} \mathrm{O}$ & 1.0 & 1.3 \\
$\mathrm{SiO}_{2}$ & 65.0 & 67.3 \\
$\mathrm{TiO}_{2}$ & 0.8 & 0.8 \\
$\mathrm{Total}$ & 99.6 & 103.0 \\
\hline
\end{tabular}

The elemental composition of the pit 1 ISV melt was input into a model of silicate melt viscosity as a function of temperature. The model of melt viscosity versus temperature (Shaw 1972) is based on a limited range of elemental compositions and may not provide the best estimate of ISV operating temperatures. It is usually assumed that ISV operating temperature is approximately the temperature of 100 poise viscosity (T100P). However, the model, which predicts a T100P of over $2000^{\circ} \mathrm{C}$ for a pit 1 melt composition, must be significantly incorrect.

First, Shade and Piepel (1990), using a sample of ORNL soil virtually identical in composition to the pit 1 soil, measured a T100P of $1735^{\circ} \mathrm{C}$. Second, pit 1 soil was used previously in an engineeringscale test melt in 1995 where a type-C thermocouple measured an ISV operating temperature of $1750^{\circ} \mathrm{C}$.

Third, when a type $C$ thermocouple was pushed into the pit 1 melt immediately after the OAT, it approached $1475^{\circ} \mathrm{C}$ as a maximum reading after about $5 \mathrm{~min}$ of immersion in the melt body. It should be noted that the thermocouple was inside a steel Geoprobe drill rod, which may have buffered the apparent temperature reading near the melting point of steel (ca. $1500^{\circ} \mathrm{C}$ ). However, when the thermocouple/rod was pulled from the melt, the steel had been melted from the end of the thermocouple.

Fourth, the melting code also predicts a T100P for the feldspar starting sand of over $1900^{\circ} \mathrm{C}$ whereas laboratory crucible tests have shown the feldspar sand to be completely melted after an hour of exposure to $1200^{\circ} \mathrm{C}$; the supplier of the feldspar sand specifies a melting point of just under $1200^{\circ} \mathrm{C}$ for the product. A redeeming aspect of the melting code, however, is that it accurately predicted the T100P 
of the melt composition used in the 1991 ORNL pilot-scale test, which was a mixture of soil and limestone; the model predicted a T100P of about $1400^{\circ} \mathrm{C}$, whereas the measured ISV operating temperature was slightly over $1500^{\circ} \mathrm{C}$. Thus, assuming that the model overpredicts pit 1 ISV operating temperature and T100P by approximately $300^{\circ} \mathrm{C}$, an actual ISV operating temperature for pit 1 operations is predicted to be approximately $1600^{\circ} \mathrm{C}$. This is consistent with the general conclusion that an unamended pit 1 soil would process at about $1750^{\circ} \mathrm{C}$ and that the ISV processing temperature would be lowered by the addition of a sodium- and potassium-rich silicate like the feldspar sand.

\section{PROCESS PERFORMANCE AND PERFORMANCE DATA SUMMARY}

\subsection{PRIOR ISV OPERATIONS DESCRIPTION}

ISV melt operations at pit 1 were initiated on April 3 at about 10 a.m. At that time, the off-gas treatment system was started and final operational readiness checklist items were addressed and completed throughout the day. At about 9:45 p.m., power delivery to the soil was achieved to initiate the OAT portion of the project. The OAT was planned to run until the melt was determined to have reached a depth of no less than $2 \mathrm{ft}$ above the known radioactive contamination layer (at a depth of $24 \mathrm{ft}$ from original pit 1 grade). The melt progressed at a downward rate of about $1 \mathrm{ft}$ per day (1/2 in. per hr) as measured by electrode depth. The target depth for the OAT was reached at about 12 noon on April 15 at which time the OAT evaluation portion of the project was initiated. The OAT evaluation lasted about 3 days, with melt 1 (melting the remainder of the setting into the radioactive zone) being initiated at about 6 p.m. on April 17. The depth objective of melt 1 was primarily to incorporate the radioactive zone, so melting to a depth of at least $26 \mathrm{ft}$ below original grade was desired. As a secondary objective, it was desired to continue melting in an attempt to determine the depth limit to which such ORNL sites could expect to be melted.

During melt operations, there were always at least four people on site. Three operators required for the ISV process system. The operations schedule was divided into three overlapping 8-hr shifts. On each shift there was a shift engineer, who was very familiar with the ISV equipment and experienced in the ISV process. The other two ISV personnel were operators, usually having minimal direct ISV experience. All ISV operations staff were trained via classroom and hands-on training, which was approved and documented by the ISV equipment supervisor. During operations, at least one staff member is required to remain in the control trailer at all times to monitor the process control equipment. Other staff members may be found at various locations around the site at various times, consistent with their job responsibilities, adjusting equipment, collecting data, or just making observations about the process. The fourth staff member was a health physics technician (HP) assigned for 24-hr coverage of the project, provided in two 12 -hr shifts per day.

Routine activities that required entry to the exclusion zone (and thus proximity to the hood) included water level monitoring, off-gas sample monitoring, and roughing filter adjustments. There were no routine activities on the hood working platform, except for adding electrode sections to the electrode column. This required four people. Two or three electrode sections were added to each electrode column at separate times during the run. 
The purpose of the OAT was to observe equipment and operator performance and to make any adjustments as required or necessary. Since there were a number of new equipment components as well as an operational crew with minimal ISV experience on the DOE large-scale ISV system, it was expected that some equipment, procedural, or personnel changes would be necessary. However, the assessment of the operations during the OAT showed that there were no major issues to be addressed or resolved by the time the OAT evaluation portion was begun. Several relatively minor problems/issues were encountered during the OAT; a description of the situation and its resolution follows:

\subsubsection{Acute Issues}

\subsubsection{Stepdown voltage potentials}

Because of the high voltages used in ISV melt operations, it may be possible to generate step down potentials some distance from the ISV hood system. It has been measured on several previous ISV melts at all scales that such a step down voltage potential does not actually exist. It is also standard procedure as a safety precaution for operators working near the hood system when melt power is applied to wear high voltage boots and gloves. However, it was thought by some that the different conditions at pit 1 relative to past ISV operations could lead to step down potentials that had not been observed previously. Therefore, an array of rods was driven into the ground so that the step down potentials could be measured. The measurements were obtained during the early stages of the OAT when the voltage levels were at their peak (about 1000 volts per phase on this test). Step down potentials were measured in the millivolt range and it was determined that there would not be a risk of electrical shock due to a step potential (i.e., $>50$ volts within a 3-ft distance).

\subsubsection{Loss of independent phase voltage control}

On April 7 at about 6 a.m. (Easter Sunday morning), a problem occurred with the B phase of the $3750 \mathrm{kVA}$ transformer secondary. The problem manifested itself with loss of voltage control at the $B$ phase controller and a temperature on the $B$ phase saturable core reactor that reached the high alarm $\left(90^{\circ} \mathrm{C}\right.$, with normal operations being at about $\left.40^{\circ}-50^{\circ}\right)$. After a day of trouble shooting, the problem was temporarily repaired/resolved at about 4 p.m., and full power was again restored to the melt. Over the course of the next several days, the suspect components were removed for evaluation. The problem has still not been completely resolved.

\subsubsection{Scrub system 1 pump repair}

On April 8 at about 4 p.m., a problem with the \#1 scrub system's pump motor was encountered. The problem manifested itself with elevated motor current and loss of pump pressure. The problem was temporarily and immediately remedied by switching the process over to scrub system \#2, per operational procedure. Over the course of the next several days, the motor (suspected of having a bad bearing) was removed, and a spare was installed in its place. After several days, the \#1 scrub system was brought back on line.

None of these acute issues contributed to any increased personnel stay time in the exclusion zone near or on the hood system. 


\subsubsection{Chronic Issues}

\subsubsection{Off-gas sampler problems}

Throughout the OAT portion of the melt and into the melt 1 portion, trouble was experienced with the various off-gas samplers being employed on the test. These included the following:

4.1.2.1.1 Graseby-Andersen sampler. The Graseby-Andersen tape samplers that were drawing a sample from the off-gas line between the roughing filter and the prefilters and the sampler on the hood experienced broken tape because of moisture. The problem was finally remedied by installing a hand held hair dryer to blow across the sample collection area to keep the tape dry. It was the Graseby-Andersen tape sampler drawing sample from the hood plenum that was located on the base frame of the hood in the exclusion zone that contributed to increased stay times. The difficulties associated with the MM5 samplers or other samplers did not contribute to increased stay times.

4.1.2.1.2 Modified method 5 (MM5) sampler. The MM5 samplers that were drawing a sample from the off-gas before and after the HEPA prefilters continued to draw moisture from the impingers back through the particulate filter, compromising the sample. The problem was never completely solved although the last attempted remedy of cleaning the check valve was not tested because of the melt expulsion incident.

4.1.2.1.3 Off-gas stack sampler. The AMS-4 sampler drawing a sample from the off-gas stack continued to experience spurious alarms due to radon collection, in spite of its inherent capability to correct for radon (alpha radiation). This problem may have been related to the excess moisture impinging on the sample filter resulting in discharge of the unit's proportional detector.

\subsubsection{Roughing filter}

The roughing filter used on the new ISV off-gas hood was a bag house designed to shake the particulate off the bags and drop it back to the melt surface. There are 128 individual bags (8 rows of 16 bags). Each bag assembly consists of a high temperature fabric (Nextel by $3 \mathrm{M}$ Corp) clamped to a 4-ft-long, 6-in.-dia. support cage. Each cage has a flange on top and is inserted vertically into a tube sheet and restrained and sealed by a hold-down mechanism. The bags are shaken by a pulse of air blown into the bag assembly from a pulse pipe, one of which is arranged over each row of bags. The pulse of air is controlled for pressure, duration, and interval. Since this was a prototypical application of the bag house design, it was expected that some adjustments would be required.

It turned out that experimental adjustments were made frequently to the roughing filter pulse controls. During the many days of the OAT, an operational procedure became established that related melt power to roughing filter control; during periods of high power $(>1800 \mathrm{~kW})$ it appeared that particulate generation increased such that the $\triangle \mathrm{P}$ across the roughing filter approached the design limit of 10 in. w.c. When this occurred, it appeared that the air pulse system was unable to sufficiently clean the bags so the roughing filter had to be bypassed for a short period (usually 15 to $30 \mathrm{~min}$ ) to allow the bags to be sufficiently cleaned. It became operational procedure to try to keep the power levels between 1500 and about $1800 \mathrm{~kW}$, depending on the $\Delta \mathrm{P}$ of the filter housing. The fairly frequent adjustments to the roughing filter air pulse controls and the compressor air supply pressure contributed to increased stay times in the exclusion zone. 


\subsubsection{Electrode feed hoists}

Electrode feeding was accomplished via a system that employs an electromechanical chain hoist to support and vertically position the electrode. One hoist is used at each of the four electrode stations. One of the hoists was damaged by water infiltration at the control panel on the hoist before the OAT was initiated. A manual chain fall was obtained and used in its place so that the melt could start. This necessitated access to the working platform to adjust the manual hoist and lower the electrode. This was typically accomplished about once per shift $(8 \mathrm{hr})$ and usually in combination with other activities requiring access to the working platform.

\subsubsection{Hood viewing ports}

The ISV hood was designed with 6 view port-access locations, 1 on the middle of each side wall and 2 on the top of the hood. Two locations were selected to install a high temperature video camera. One of the camera ports was located on the top of the hood near the center, while the other was located at a view port on the side wall of the hood. This left 3 viewports on the side and lon the top for direct observation.

The use of the cameras was intended to reduce, if not eliminate, the need for personnel to access the hood for routine viewing purposes. The cameras included an air sweep system designed to keep the glass protecting the camera lens free of particulate. The three remaining viewports on the side of the hood included a damper mechanism that was also designed to minimize particulate buildup on the windows. However, neither the air sweep on the cameras nor the mechanical damper on the viewports were able to keep the windows adequately free of particulate for a clear view of the melt. Also, the camera system on the top of the hood, looking directly down onto the melt, apparently malfunctioned early in the run and could not be repaired at that time.

The particulate generation on the windows hindered the collection of visual data from the melt. It was possible to view the melt from the top sight glass when personnel were on the working platform, and occasionally through small apertures in the side viewports where the particulate loading was low. Efforts were made to clean the view port windows occasionally during the run but the clear view was typically short lived. As a consequence of the lack of visual data collection capability, very little data were collected on the performance of the vent pipes because the position of the vent pipe socks could not be readily ascertained.

\subsubsection{Off-gas flow rate design uncertainty}

Over the course of operations, an issue related to the off-gas flow rate developed. It appears that the flow rate being drawn from the hood is about twice that for which the prefilter and roughing filter systems were designed based on an erroneous design specification. That is, the off-gas system is designed to pull a maximum of about $104 \mathrm{standard} \mathrm{scm} / \mathrm{min}$ of air. However, according to design data and incorrect information provided at the time the filter system were designed, the off-gas system is designed to operate normally at between 40 and $60 \mathrm{scm} / \mathrm{min}$. Therefore, the filter systems were designed for a maximum flow of about $60 \mathrm{scm} / \mathrm{min}$. It should be made clear that exceeding the design flow rate does not compromise any safety aspects of the equipment, it merely reduces its filtration performance efficiency.

This lack of performance efficiency contributed to some of the increased stay times in the exclusion zone as operators tried to optimize the operation of the roughing filter under the current conditions. It 
contributed to an increased usage of HEPA filters in the prefilter system since the $\triangle \mathrm{P}$ increased more rapidly than otherwise would have been experienced. The actual flow rates as well as potential modifications to the filtering hardware will be examined before the next run is initiated.

\subsubsection{Melt monitoring thermocouple array malfunctioning}

During the site preparation activities of the preceding year, an array of type $\mathrm{K}$ and type $\mathrm{C}$ thermocouples was installed in the soil surrounding the projected region of the first melt. For various reasons, almost all of the thermocouples failed during the early stages of the OAT. After that, there was no accurate indication of the melt front thermal profile or the melt temperature as was designed to be obtained by the thermocouple array. While this did not contribute to increased stay times in the exclusion zone, it did contribute greatly to a lack of understanding of the melt temperature, melt growth and moisture profiles in and around the melt region. The failure also required the placement of an additional four thermocouples on the north and south sides of the off-gas hood at a depth where an enlarged melt body could be detected before it might undercut the perimeter of the off-gas hood. The placement of these extra thermocouples is discussed subsequently.

\subsubsection{Caustic solution preparation problems}

The addition of caustic solution became complicated when the supply of liquid sodium hydroxide was depleted after only a few days. The intention was to add concentrated liquid caustic solution to the scrub tanks via the caustic tank addition procedure and avoid handling solid caustic pellets. Once the liquid caustic supply was depleted, the standard procedure was to mix solid caustic pellets and water to form the caustic solution to be added to the scrub tanks. A sufficient supply of liquid caustic will be obtained for the next runs. (Caustic solution is required to maintain the scrub solution in a pH-balanced condition; without it, the scrub solution becomes very acidic because of the nature of the off-gases generated by the ISV process. Processing highly acidic scrub solution contributes to deterioration of scrub system components and generates a hazardous waste.)

At one point in the run, the transfer linkage for the piston pump on the caustic addition system broke. It was temporarily repaired but needs to be replaced. The use of solid caustic material did not contribute to an increased stay time in the zone; it did, however, create an additional safety hazard for ISV operators, which had to be managed and can be avoided.

\subsubsection{Hood compressed air supply problems}

The hood system compressor developed a problem in which the compressor would not automatically start up once it reached its low pressure set point. For several days, this was an intermittent problem. Operators would have to judge when the compressor was depleted and go out and manually reset the compressor so it could recharge. The problem was eventually solved by one of the shift engineers. Since the compressor provided the pulse air for the roughing filter blowback cycles, the malfunction of the compressor contributed to the poor performance of the roughing filter during this period. The compressor control is mounted on the hood frame and required an entry to the exclusion zone for trouble shooting and reset procedure.

\subsubsection{ISV vent pipe monitoring system inoperability}

The subsurface vent pipe operational assessment technique provided no information on vent pipe performance. The movement of ceramic wind socks attached to the tops of various vent pipes was to provide visual evidence of their conducting off-gas into the hood from the subsurface. During the entire 
OAT, only one wind sock could be seen from the north viewport window. It was lying on the Cerwoolcovered ground surface and appeared bloated or rigid with what could possibly be expelled mud from the vent pipe. When the off-gas hood is moved, an effort will be made to systematically find and evaluate the condition of all socks and determine the residual open intervals of all pipes. As discussed subsequently, a better system to determine vent pipe performance must be identified for future ISV operations so their functional status can be evaluated in real time.

\subsubsection{Operational Acceptance Test (OAT) Evaluation}

During the "down time" of the OAT evaluation period, several planned procedures were conducted. These included removing several bags from the roughing filter for sampling (and replacing them with clean ones), inserting a rod into the melt to remove a sample of the glass and taking smear samples of the inside of the off-gas hood and piping equipment, as available. An overall evaluation of the process and operations showed that they were working very well, and in that light, the previously listed problems were considered minor.

An effort was made to repair the damaged electrode hoist, but the repair parts obtained were not correct. Efforts were also made to clean off the view ports but they were short lived. An effort was made to remove the malfunctioning camera (to attempt to repair it), but an evaluation of this effort showed that it would take more time and resources than could reasonably be committed then, so the effort was abandoned. New holes were driven into the pit for thermocouple placement, one each on the north and south ends, in an effort to make up for the lost thermocouple data mentioned above, and specifically, so that the outward growth of the melt could be monitored relative to the size of the off-gas hood.

During the period of the OAT evaluation, when activities were not being conducted in the vicinity of or on the hood, power was applied to the melt at an "idling" rate of about $1 \mathrm{MW}$. The basis for applying the low power level was to try to preserve the melt temperature without advancing the melt while the evaluation (of undetermined duration) was being conducted.

Once the evaluation was completed and the approval was given to continue melting, melt 1 was initiated at about 6 p.m. on April 17. All operations and activities continued without additional problems until the melt expulsion incident, although radiation dose rates in the vicinity of the hood were increasing as expected.

\subsection{ISV PROCESS PERFORMANCE DATA BEFORE AND DURING MELT EXPULSION INCIDENT}

\subsubsection{Electrode Depth Versus Time}

The manually collected data on the penetration of the four electrodes into the melt body as a function of time in presented in Fig. 10. At the time of the melt expulsion incident, two characteristics of the electrode penetration information would seem worthy of note. First, the average electrode depth was approximately $10 \mathrm{ft}$ below the elevation of perched groundwater within pit 1 as measured at the two monitoring wells immediately to the north and south of the off-gas hood. Pit 1 ISV had been operating under such conditions relative to the pit's perched water since the start of operations when seeping water had to be pumped out of the startup trench.

Second, one electrode had been lagging significantly behind (approximately $1 \mathrm{ft}$ less penetration) the other three electrodes. At the time of the melt expulsion incident, this lagging electrode was 


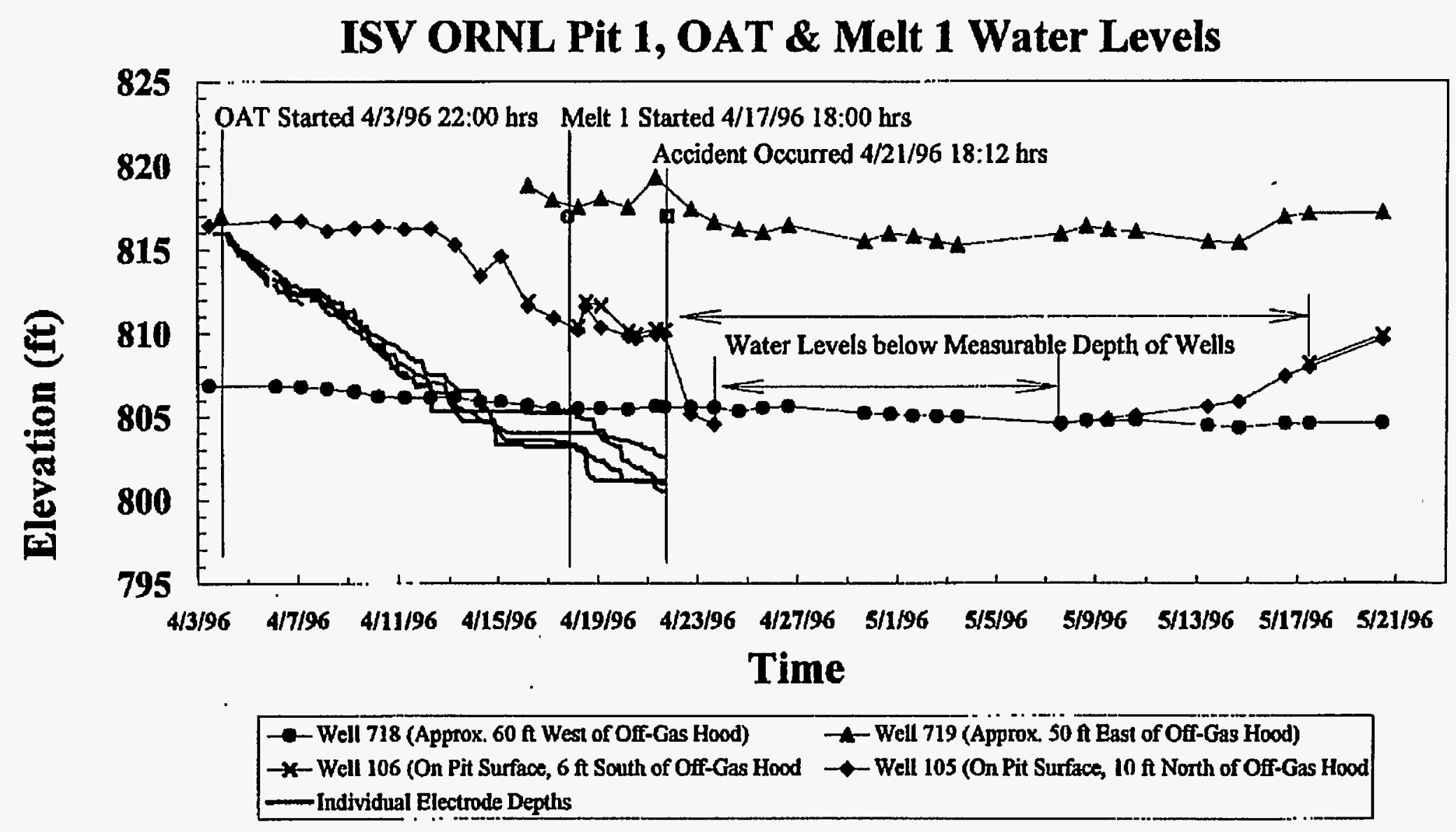

Fig. 10. Depth of ISV electrode penetration into the ORNL melt as a function of time and its relation to groundwater elevation within and around pit 1 
continuing to make depth progress, like the others, indicating that it was not stuck or frozen into a cold cap on the melt body. Such an electrode profile and the breakage of the other three electrodes earlier in pit 1 operations was not considered unusual for large-scale ISV melts by the experienced PNNL or Geosafe staff.

\subsubsection{Off-Gas Hood Temperature and Vacuum}

Two obvious characteristics of the hood were grossly perturbed by the expulsion of glass during the melt expulsion incident; hood vacuum and temperature. The data acquisition system, however, only saves 4-min average characteristics of the data monitored by the process control system (the two Bailey computers). Thus, because both the hood temperature and vacuum (or pressure during the melt expulsion incident) were quite transient, the archived data is not useful to determine the necessary resolution of these parameters to understand the dynamics of the melt expulsion incident.

The archived data are useful to determine if trends that indicated something unusual was about to occur were apparent. However, the data both in the short term and over the entire length of ISV operations at pit 1 show no obvious indicating trends. For example, the temperature of off-gas in the hood plenum (Fig. 11) indicated quite stable conditions during the $20 \mathrm{~h}$ prior to the event. Small fluctuations like that which occurred around 3:21p.m. on April 21 were the result of adjustment of the hood's air-intake valve (PIC-101) or a change in HEPA prefilters. There is no trend of increasing or decreasing hood off-gas temperature prior to the melt expulsion. The "spike" in the off-gas temperature near the end of the data collection period shows the influence of increased off-gas temperature on a 4-min average, much-dampened intensity (Fig. 11).

The vacuum. in the off-gas collection hood obviously went considerably positive, i.e., pressure, when the hood was lifted off the ground during the expulsion event. Routinely, the hood was maintained under slight vacuum (i.e., $0.25-0.50$ in. of water column). Hood vacuum was varied over the duration of the melt operations due to operator adjustment of the air-inlet valve or application of water by hose or rainfall to the soil and sand around the hood base to improve its seal to the ground. Examination of detailed data during the $20 \mathrm{hr}$ before the melt expulsion (Fig. 12) reveals the same lack of indicating trend prior to the melt expulsion incident.

\subsubsection{Electrical Power Characteristics}

An obvious question concerning the cause of the melt expulsion was whether electrical power to the melt body had been turned up prior to the melt expulsion incident and, unwittingly, lead to the "boil over" of the melt body contents. Of course, selection of the level of power to the melt involves some ISV process judgment and inherent process and equipment restraints. Voltage to the electrodes is the parameter adjusted by the ISV operations personnel, and the resulting amperage is monitored and kept within the limitations of the power cables to the melt. The resistance of the melt itself determines what current will flow at a given voltage setting.

Power is turned on and off quite frequently during any ISV operation for a variety of equipment adjustments in the electrical safety zone on the hood work platform. The level or amperage and voltage to each of the two phases to the melt body did not show any umusual fluctuation or trend during the entire 18-day interval of ISV operations; the ISV shift engineer, at the time of the melt expulsion incident, did report unquantified fluctuations in the voltage and current approximately $10 \mathrm{~min}$ before or during the melt expulsion but these are not reflected in the 4-min average parameters collected by the data acquisition system. The power to the melt (the product of current and voltage for both phases) showed an obviously similar trend over the 18-day interval (Fig. 13). It can also be seen that the level of power, 
Data Set for $4 / 21 / 96$

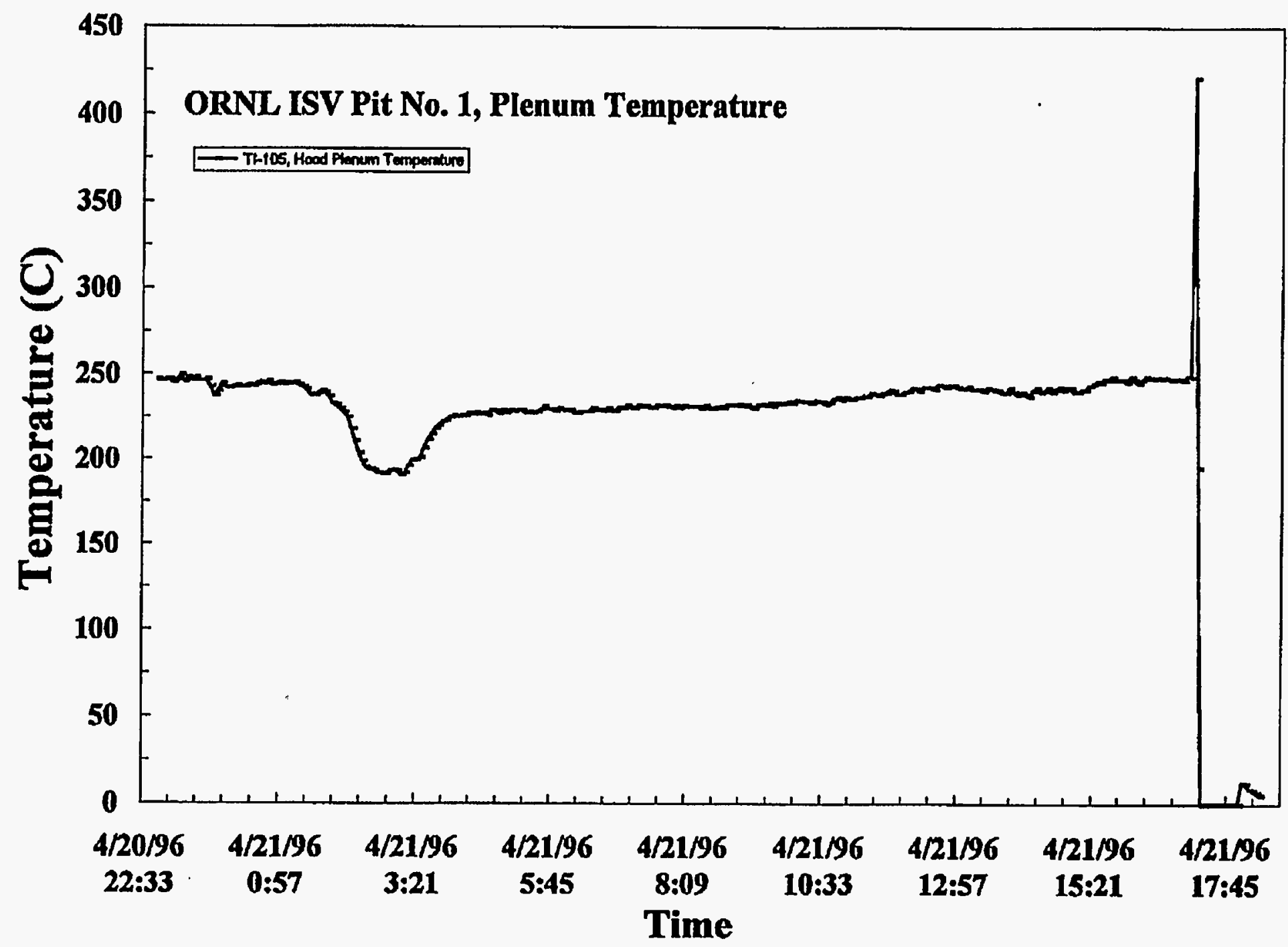

Fig. 11. Off-gas hood plenum temperature during the 20 hours immediately before the ISV melt expulsion incident of April 21, 1996, 18:12 


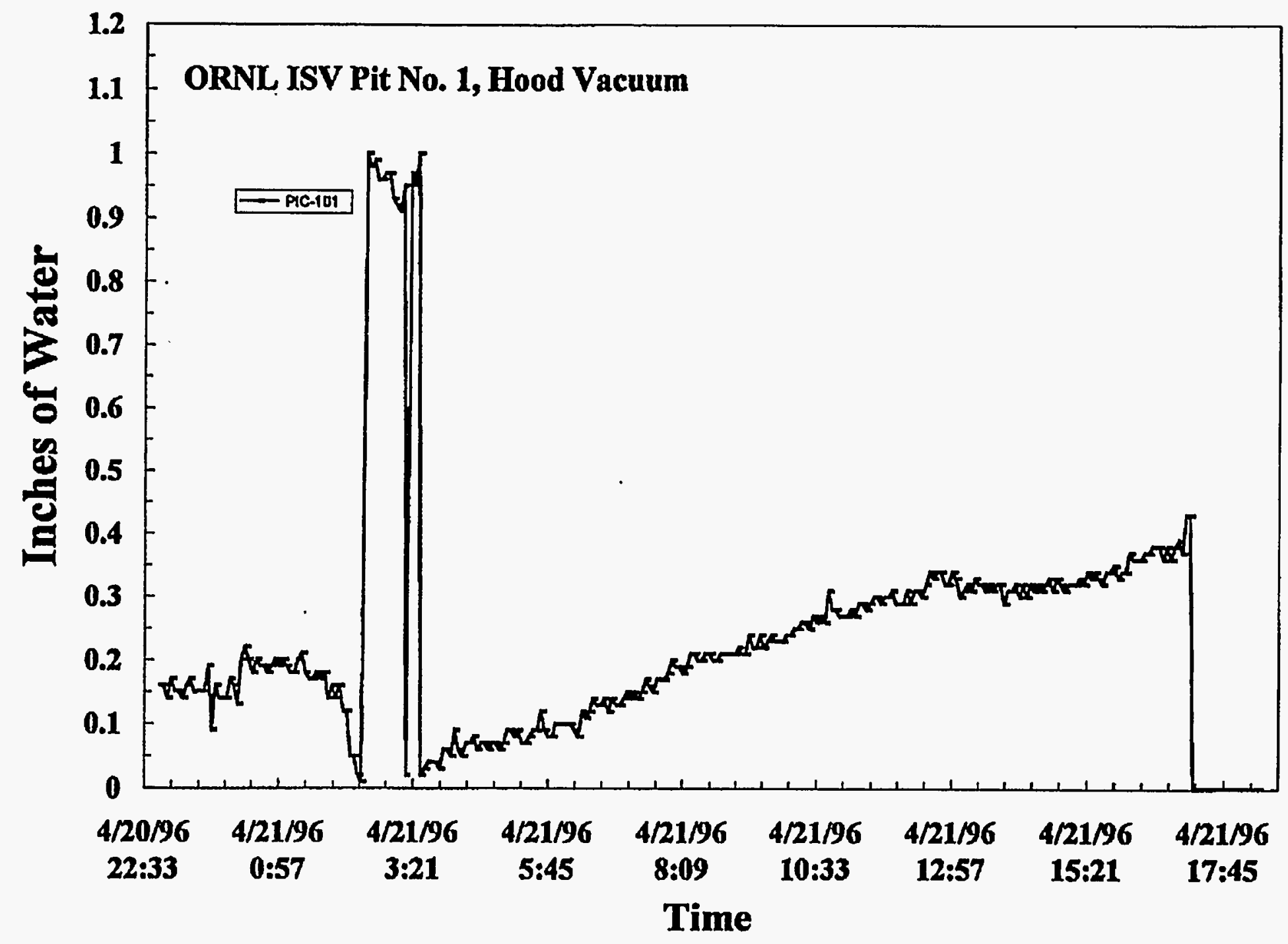

Fig. 12. Vacuum within the ISV off-gas collection hood during the 20 hours preceding the ORNL ISV incident of April 21, 1996, 18:12 


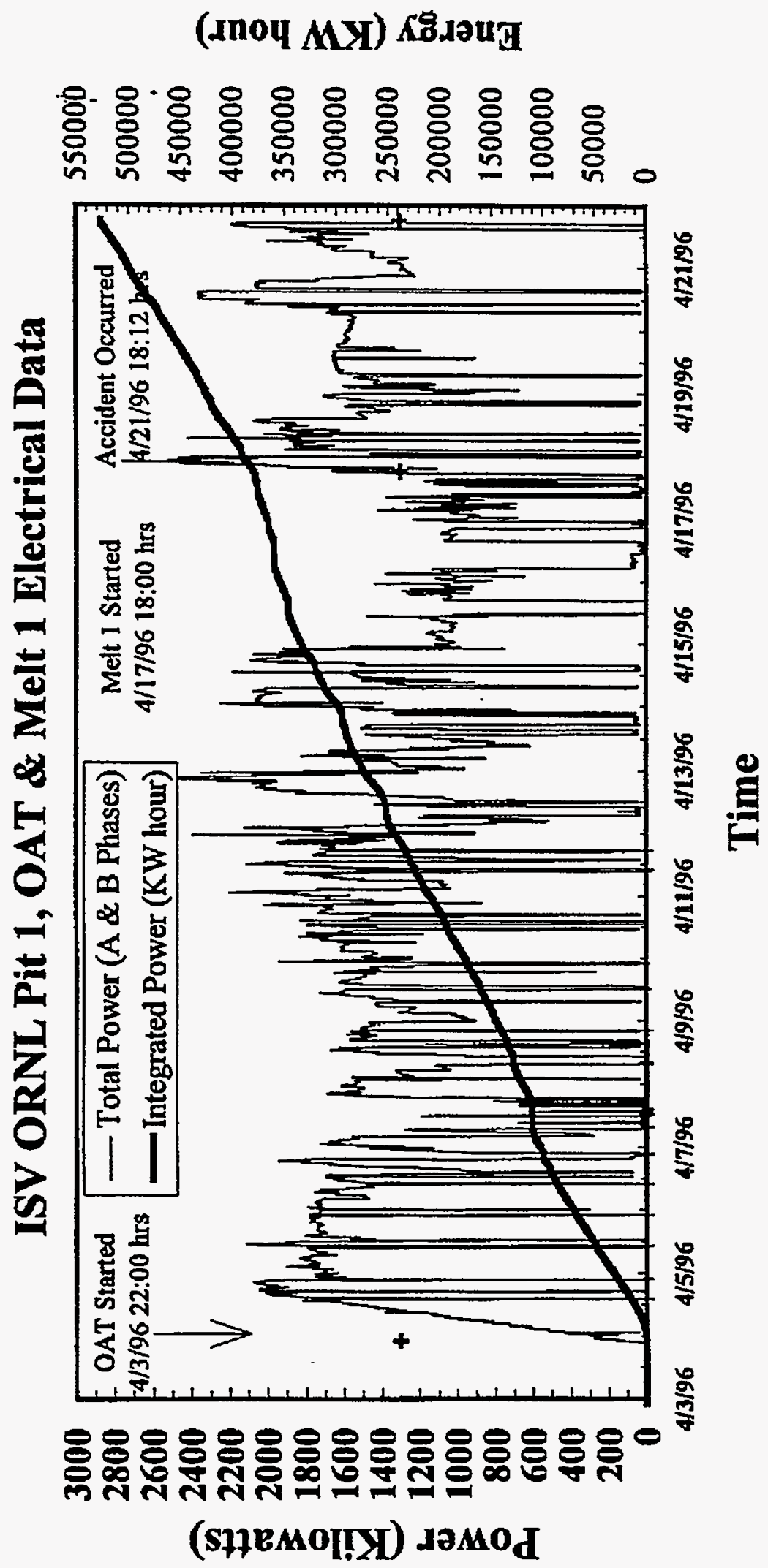

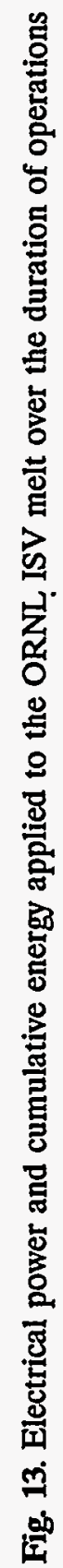


which was being delivered to the pit 1 melt at the time of the melt expulsion incident, was not the highest applied during operations; many other times previous to the melt expulsion incident, power levels had been significantly higher. Power was usually adjusted in response to hood off-gas temperature; when hood plenum temperatures exceeded about $300^{\circ} \mathrm{C}$, power was routinely reduced to a level that would maintain off-gas temperature below that level.

The cumulative power delivered to the melt can also be seen in Fig. 13. As discussed previously, cumulative power is useful for estimating melt mass. More importantly, the slope of cumulative power versus time is a more convenient indicator of energy to the melt because it avoids the shorter-term fluctuations apparent in the actual power data. It can be seen from Fig. 13 that the slope of the cumulative power at the time of the melt expulsion was not significantly different than at other times during the 18-day interval.

Examination of electrical power characteristics during the $20 \mathrm{hr}$ immediately before the melt expulsion (Fig. 14) does not reveal any obvious trend other than a gradual stepping up of power. The brief period of power outage about $2 \mathrm{hr}$ before the melt expulsion was due to entry to the hood's work platform to perform a radiation survey and to adjust electrodes. Four personnel were on the work platform at that time and this graph indicates that these personnel could likely have been on the work platform during the melt expulsion had tasks been delayed.

During the periods when the pit 1 melt was operating optimally, a typical total power of $2 \mathrm{MW}$ was being applied. Attempts to raise this power input always resulted in overheating of the ISV off-gas and hood skin temperatures and required power reduction. Actually, when viewed on a power density basis, the pit 1 melt was typical of many large-scale ISV melts, which are typically deployed with greater spacing between electrodes. The 10-ft electrode spacing selected for the initial melt in pit 1 corresponds to a power density of $0.02 \mathrm{MW} / \mathrm{ft}^{2}$, assuming $100 \mathrm{ft}^{2}$ area $(10 \times 10 \mathrm{ft})$ among the four electrodes. Using an identical power density, $4 \mathrm{MW}$ could be applied to an electrode array with a $14.1-\mathrm{ft}$ spacing. Such larger electrode spacings should be considered for the additional ISV melts in pit 1 , which could both speed up ISV melt rate (mass per unit time) and result in larger diameter melts.

\subsubsection{Water Collected From Melt}

The water distilled from the ISV melt zone was condensed by the off-gas scrub system, collected, and transferred to a tanker, which was used to transport it to wastewater disposal facilities at ORNL. The limited capacity of the ISV scrub system collection tank necessitated frequent transfers of accumulated liquid, which generated considerable data on liquid accumulation versus time (Fig. 15). The ISV equipment has two identical off-gas scrub systems to provide backup or expanded off-gas processing capacity should a problem develop with one of the two systems. The slope of the cumulative liquid volume collected in Fig. 15 is a direct measure of the rate of generation of water from the melt. Although the slope of liquid accumulation indicates a slightly greater generation rate (approximately $505 \mathrm{~L}$ of water per hour) during the 2 days before the melt expulsion incident, there was no dramatic increase in liquid generation rate, which could have been interpreted to indicate a major influx of water into the thermally active zone around the melt.

\subsubsection{Water Table Responses Before And After Melt Expulsion}

As discussed in detail under the section on the mechanism of melt expulsion, the elevation of perched water in pit 1 was being drawn down gradually by its distillation over the entire 18-day interval leading up to the melt expulsion (Fig. 16). However, when measurements of the water levels in the two wells immediately north and south of the off-gas hood were attempted on the day after the melt 


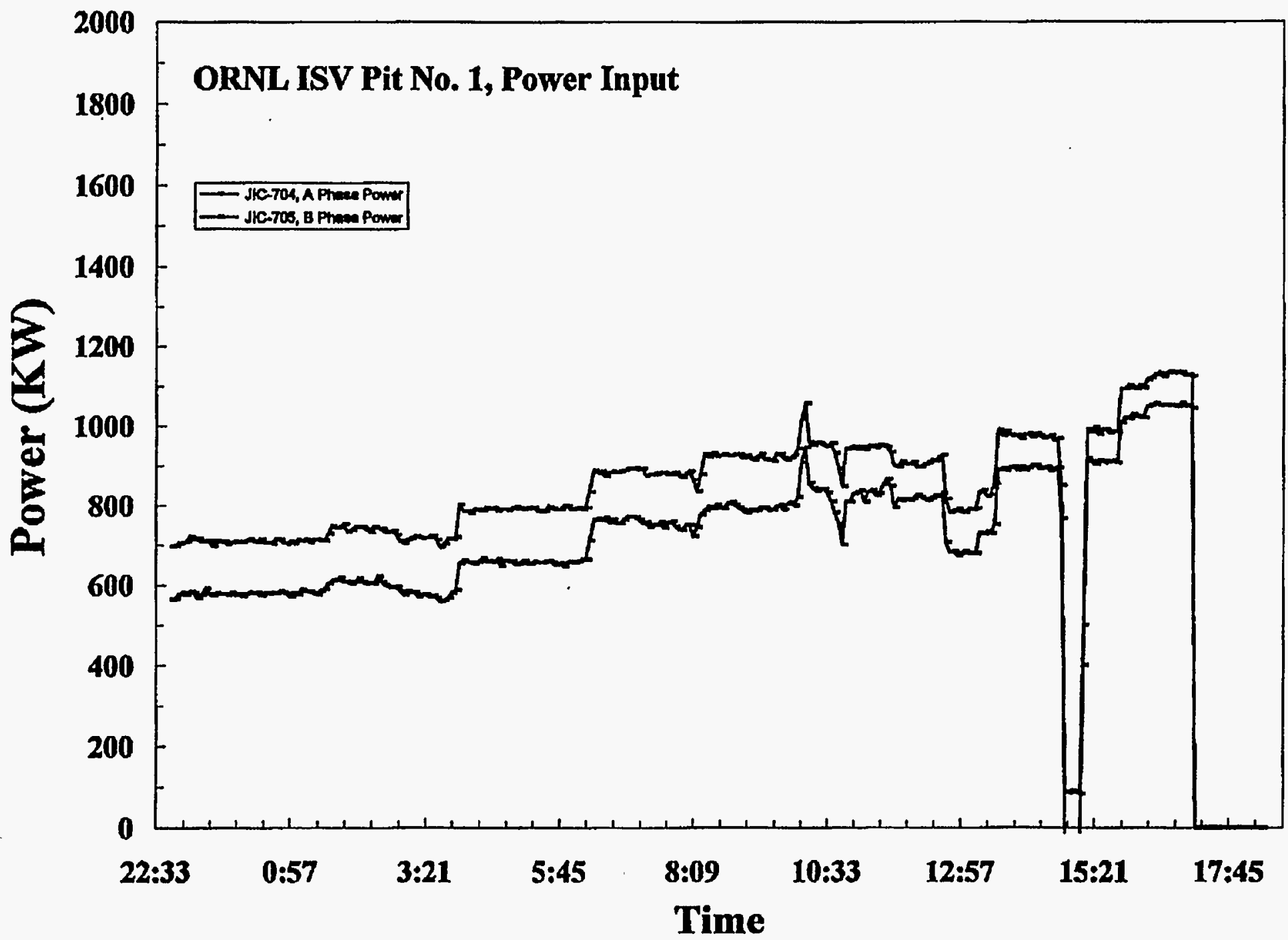

Fig. 14. Electrical power applied to the ORNL ISV melt during the twenty hours preceding the expulsion event of April 21, 1996, 18:12 


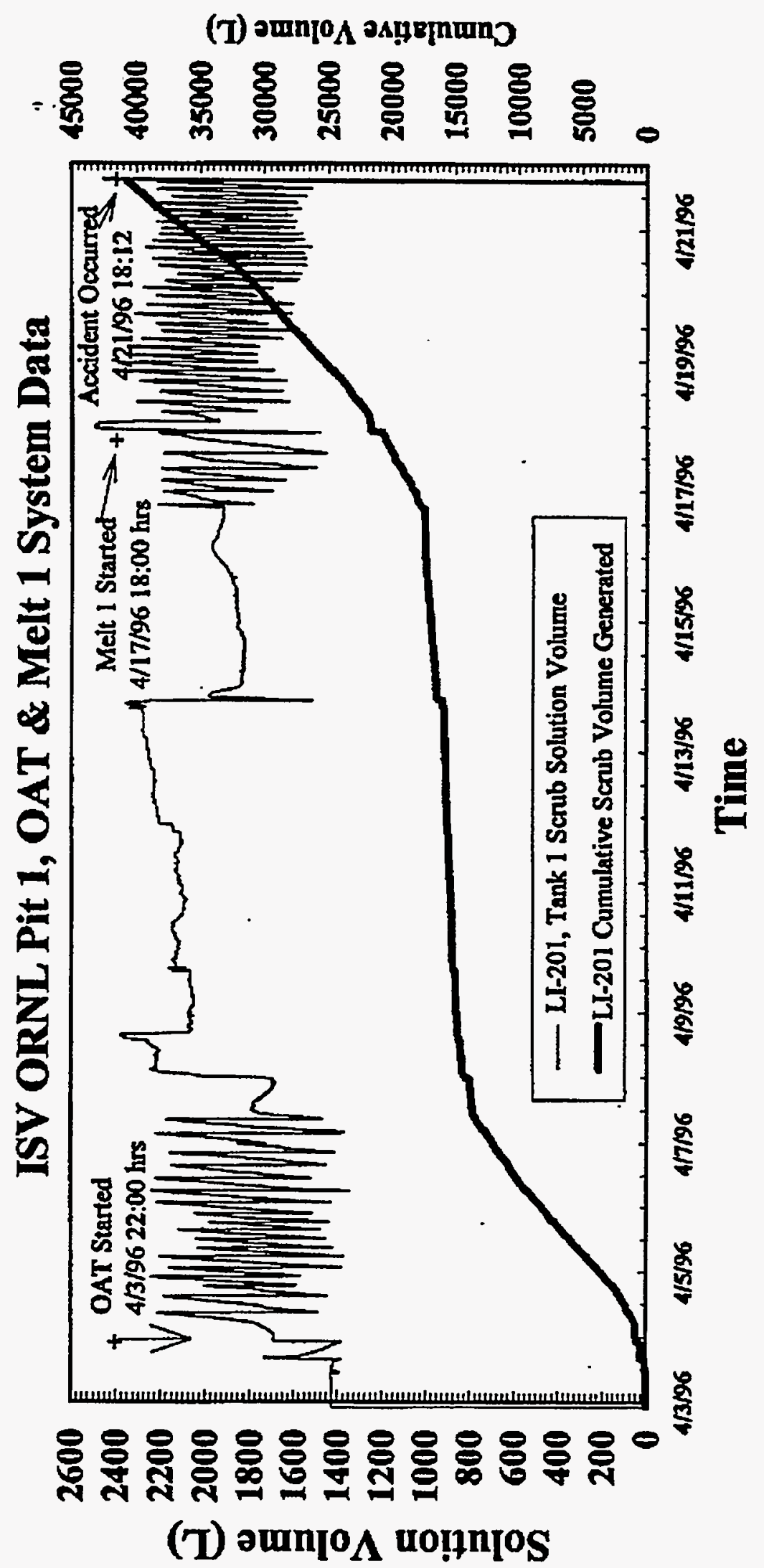

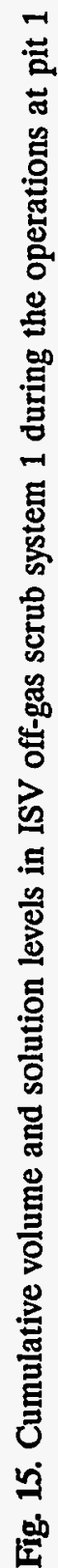




\section{ISV ORNL Pit 1, OAT \& Melt 1 Water Levels}

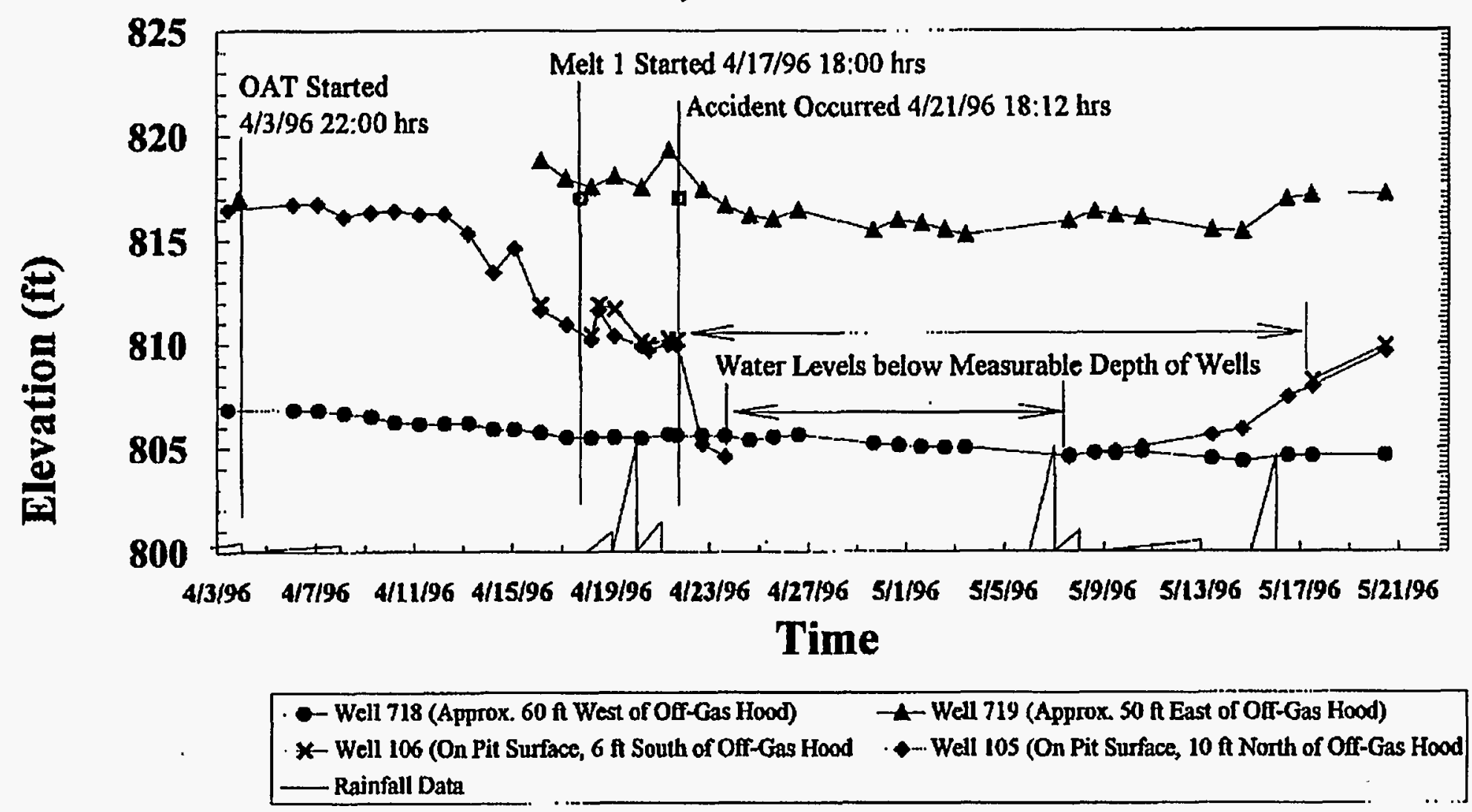

Fig. 16. Watertable elevations within and around ORNL pit 1 and precipitation during ISV operation relative to the April 21, 1996, expulsion incident 
expulsion, no water was found in either well indicating that the levels had dropped at leastan additional $6 \mathrm{ft}$ since the previous day's measurement to below the bottom of the each well. In contrast, water levels in the two wells outside pit 1 to the east and west of the pit indicated no fluctuation relative to the melt expulsion incident. Water levels as of May 30,1996, were high enough to cover the top of the melt surface in the residual startup trench/subsidence crater.

In addition to the observations of water levels in the two wells within pit 1 adjacent to the off-gas hood, the response of several thermocouples, positioned between these wells and the melt body provide additional information on the possible causes for the disappearance of water from these wells. Because of the failure of most of the buried thermocouples around the melt area, after the OAT, two angled Geoprobe rods were driven at angles on the north and south sides outside the off-gas hood. Two type-K thermocouples were then inserted in each Geoprobe rod to two different depths.

The purpose of these additional thermocouples was to provide warning if the ISV melt body were to approach a diameter similar to the width of the off-gas hood. Thermocouples were positioned at approximately 5 and $10 \mathrm{ft}$ inside the wall of the hood at depths of 14 and $22 \mathrm{ft}$ below ground surface, respectively (Fig. 17). All four thermocouples were connected to the data acquisition system (DAS) in the project office/break area portable building; data from these thermocouples were collected beginning 4 days before the event and for about two weeks after the event. Power for this DAS was not interrupted as was the process control trailer's DAS during the fire. None of the four thermocouples indicated any thermal influence from the melt body during or after the event. Thus, the disappearance of water from these two wells, further away from the melt body than the thermocouples, could not have been caused by hot pressurized steam flowing away from the melt. The disappearance of water must represent flow towards the melt body probably into dried soil around the melt which, prior to the event, must have contained sufficient pressure to counter the hydrostatic head of perched water in these wells.

\section{MECHANISM OF MELT EXPULSION}

As in past incidences of molten glass expulsions during ISV operations, the ORNL expulsion was caused by steam pressurization at some depth beneath the molten body in excess of the static hydraulic pressure of the molten body plus any structural strength resident in the melt's cold cap and surrounding sintered zone (Geosafe Corporation 1993, Roberts et al. 1992). To understand how these various components interact to conduct steam around the melt body rather than through it, the normal ISV melt body conditions need to be reviewed (Fig. 18). As can be seen from Fig. 18, the molten body is believed to have several transition zones between it and unaffected soil usually within a few inches of actual molten product. It is generally thought that the layer or rind of dry soil surrounding the molten body is very important as a conduit for steam and other hot gas to move from beneath and around the molten body to the ground surface where it is collected in the ISV off-gas hood. The total soil porosity in this dry rind is thus available for gas conductivity.

Perhaps the only salient difference between the conceptual model in Fig. 18 and actual conditions in ORNL pit $l$ is that the unaffected soil zone would have been completely saturated with water. This difference could be a significant factor in contributing to the expulsion incident in pit 1 . As depicted in Fig. 18, pressurization of steam in the dry zone has an additional potential release through the saturated $100^{\circ} \mathrm{C}$ isothermal zone into ambient unsaturated soil; such release would require only a nominal pressure to displace enough water to open some unsaturated zone to the outside. However, in the case of pit 1 , the unaffected soil was saturated and, thus, had no residual gas-filled porosity through which to conduct 


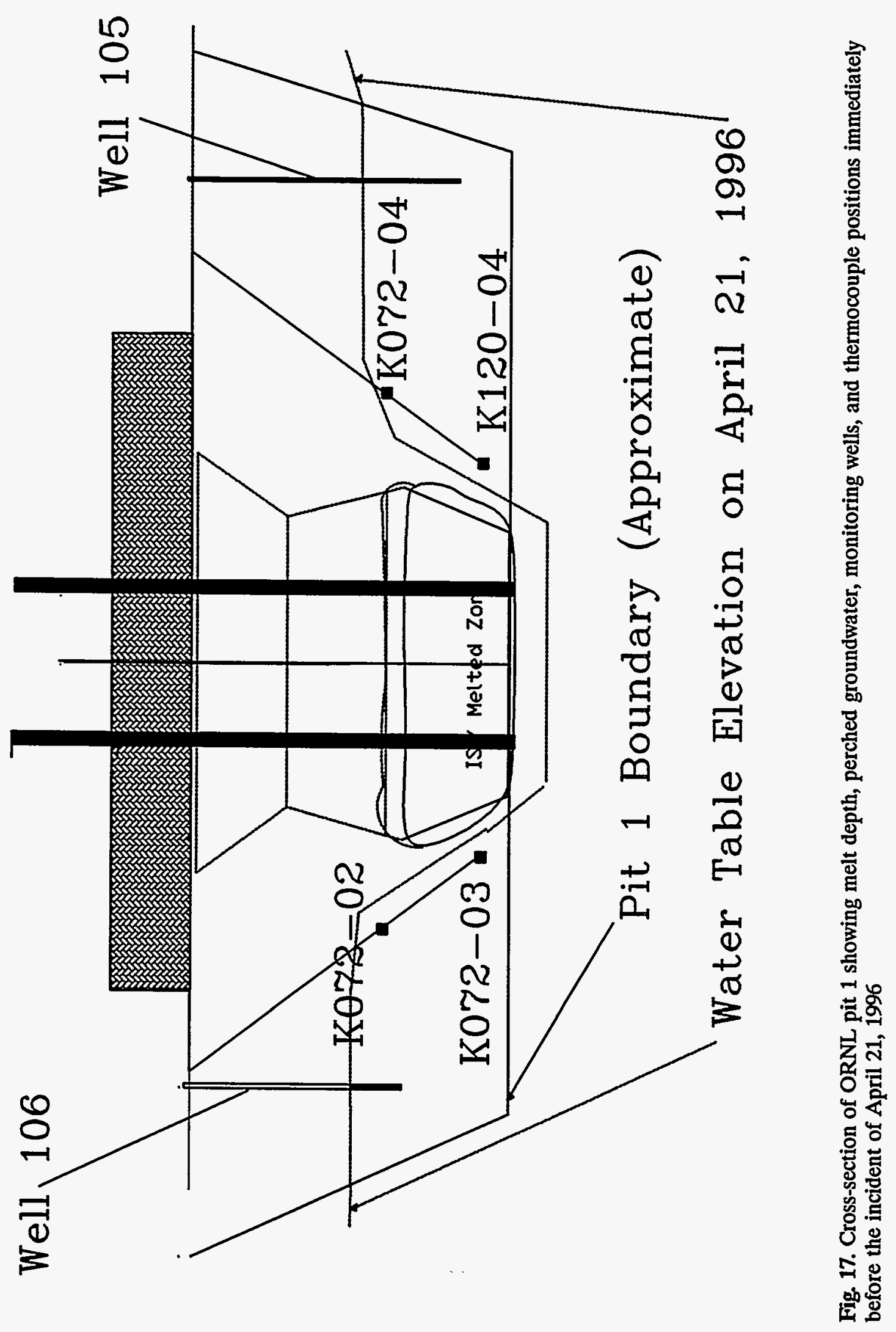




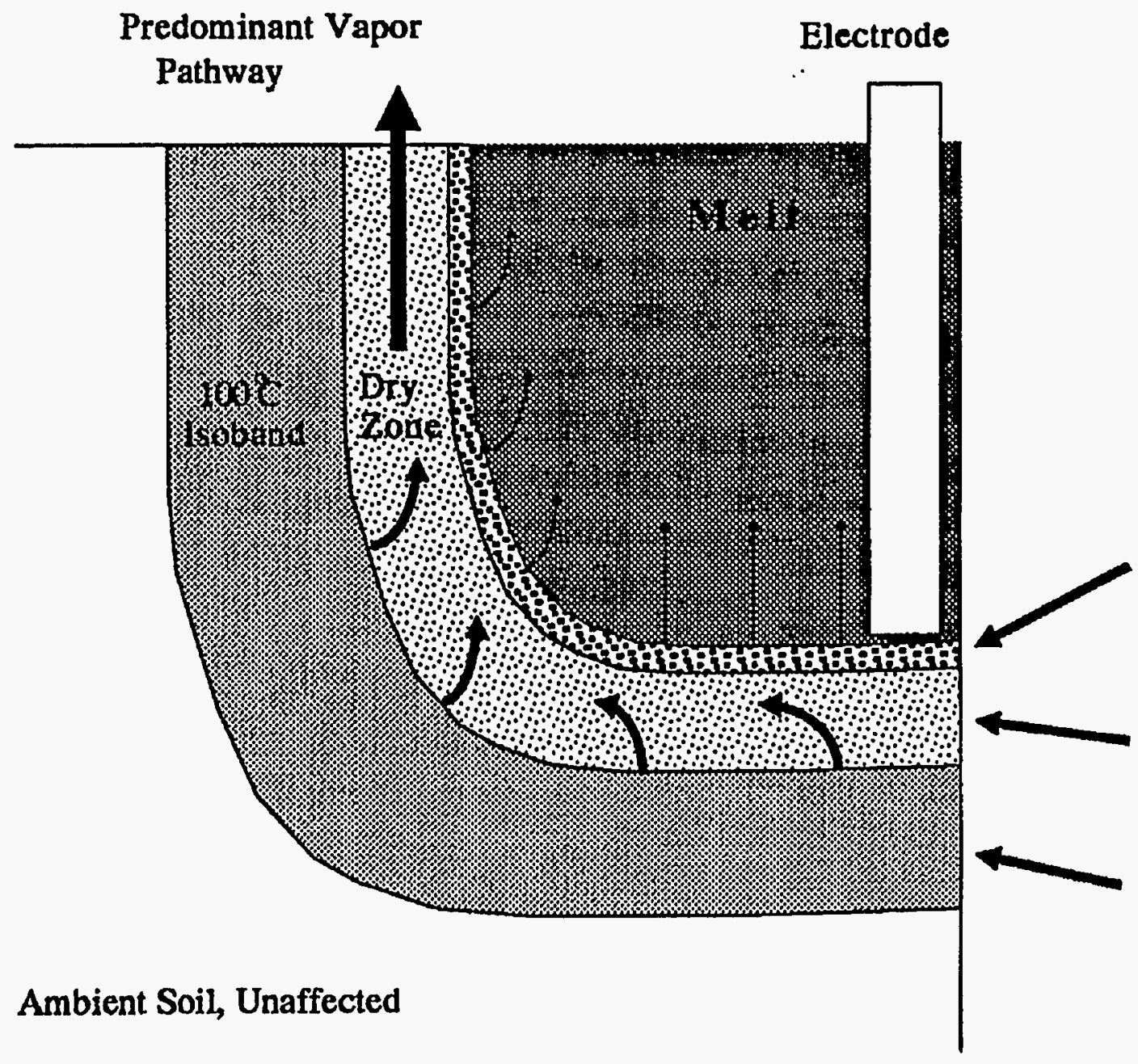

Fusion Layer (highly viscous, partially sintered, some vapor diffusion through; this layer typically is not penetrated by vapor pressure in the dry zone)

Dry Zone (no liquid phase water, highest permeability, most vapor transport)

$100^{\circ} \mathrm{C}$ isoband (full or partial saturation, low gas phase permeability, low vapor transport; net flow of vapor is toward melt and toward ground surface)

Fig. 18. Conceptual model of ISV off-gas vapor pathways around a body of molten soil 
any steam. Obviously, some residual gas-filled porosity in the unaffected soil, i.e., unsaturated conditions, would be a desirable condition to maintain this potential pressure venting pathway.

\subsection{SOIL POROSITY FOR OFF-GAS CONDUCTION}

The porosity of pit 1 soil averaged about $43 \%$ (soil bulk density of $1.5 \mathrm{~g} / \mathrm{cm}^{3}$ ) to a low of $16 \%$ for the denser undisturbed material at the bottom of the original pit (bulk density of $2.2 \mathrm{~g} / \mathrm{cm}^{3}$ ). Of course, the total porosity is not necessarily correlated with or indicative of gas permeability, which is the parameter that limits the gas conductivity of a particular material; but the denser undisturbed material beneath pit 1 is likely to be of significantly lower gas permeability than the overlying less dense fill soil. Thus, as the melt body approached this denser bottom material, restrictions in gas permeability become more likely.

In general, if the rate of steam generation is too great for the dry zone to dissipate around the melt body or if the dry zone projects into a zone with man-made obstructions, e.g., a concrete floor, residual tank floor, or extended metal barrier, steam pressure dissipation can be obstructed to the point that the least resistant pressure gradient to the surface would be through the molten body (Roberts et al. 1991 and Geosafe Corp. 1993). Such man-made obstructions have been implicated in the three previous ISV melt expulsion events. Assurance of the absence of man-made barriers in pit 1 was thought by the project team to discount the possibility of a melt expulsion.

It would seem obvious in retrospect that the denser undisturbed soil or rock beneath pit 1 could have functioned as a barrier to steam pressure release and contributed to the melt expulsion. However, the pit bottom was judged not to exhibit high integrity as it was frequently penetrated by 0.5 -in. dia. rod driven from the soil surface with an electric jackhammer. Fifteen of 63 driven rod strings penetrated up to 39 $\mathrm{ft}$ below the surface through the dense pit bottom at $26 \mathrm{ft}$. None of these other 0.5 -in. driven rods actually encountered refusal on the pit bottom; penetration tests were simply terminated when a change in penetration speed indicated contact with denser material, i.e., the pit bottom.

In contrast, the pit bottom always resulted in penetration refusal when driving the larger diameter (1.75 in) AQ drill rod; the AQ drill rod strings were used as access holes for in situ radiation detection as part of site characterization. Thus, conceiving of the pit 1 bottom as a monolithic and impermeable strata would be inconsistent with the penetration test data collected during site characterization. However, the pit bottom is significantly more dense and likely is significantly less permeable than the overlying fill soil.

\subsection{MELT HYDROSTATIC PRESSURE}

Gas permeability in the dry zone around an ISV melt body is not the only factor that restrains steam from entering the melt body. The weight of the molten fluid itself poses a significant barrier to steam entry. The density of molten fluid $\left(2.83 \mathrm{~g} / \mathrm{cm}^{3}\right.$ or $\left.177 \mathrm{lb} / \mathrm{ft}^{3}\right)$ provides a calculated hydrostatic pressure of $1.21 \mathrm{psi} / \mathrm{ft}$ of melt depth. The pit 1 melt body at the time of the expulsion was $8.97 \mathrm{ft}$ thick and, thus, would have a hydrostatic pressure of about 11 psi at its bottom. Steam could enter the melt body only if its pressure were in excess of that hydrostatic pressure. Of course, steam could enter the melt body at lower pressure at a shallower depth and still result in a bubble of significant size, which could cause a melt expulsion (Fig 19).

Assuming that the bottom of the melt is dry, the hydrostatic head difference between the melt bottom and the perched water in the pit on the north and south sides of the off-gas hood was 


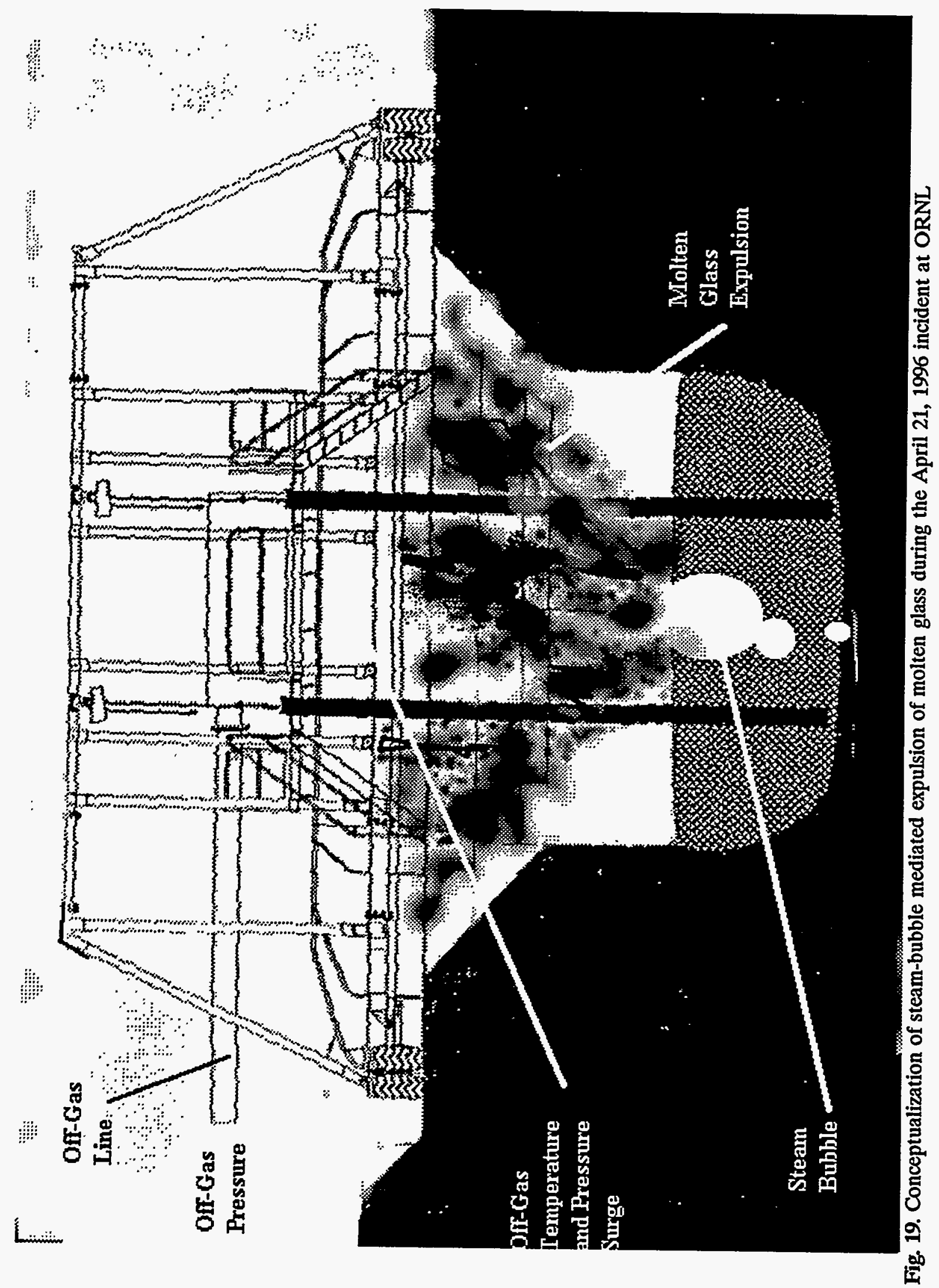


approximately $11 \mathrm{ft}$ or $4.76 \mathrm{psi}$. Such a hydrostatic pressure would not be sufficient to overcome the melt body hydrostatic (or, more correctly, lithostatic) pressure and result in water movement to the melt body. But, a steam pressure of such magnitude would be quite plausible within the dry zone around the melt body. Of course, if that steam pressure were relieved rapidly, as during the melt expulsion event, then perched groundwater could flow rapidly into the depressurized dry zone. This could account for the disappearance of standing water in the two wells within pit 1 after the melt expulsion.

\subsection{SINTERED ZONE PROPERTIES}

In addition to the static pressure of the molten body, the sintered layer or rind of thermally altered soil around the melt body poses a barrier to mechanical disturbance and, presumably, to steam entering the melt body. Sintered soil is soil that has not yet completely melted but has fused together into a bricklike material of high structural strength; it is stronger than either the dried or unaltered soil outside or the viscous molten mass inside. It provides some constraint on melt body deformations from pressures outside and inside it. Although the sintered layer is probably still permeable to steam, it likely poses some fluid conduction constraints on steam entry into the melt body.

\subsection{COLD CAP FORMATION}

Similar to the sintered zone on the sides and bottom of the ISV melt body, a cold cap or solidified layer can form on the upper surface of the ISV melt body. If the cold cap forms sufficient strength, it can function as a confining structure to melt deformation necessary for bubble growth and movement. In effect, it can function as an additional confining pressure for the melt body. Its subsequent redissolution into the melt with increased heating or partial thinning of seams within can result in a loss of this additional confining pressure. Such loss of confining pressure could well contribute to bubble growth, particularly if steam was marginally restrained near the melt bottom by its added strength.

\subsection{PRESSURIZATION BY STEAM}

Several mechanisms exist by which steam pressure could incrementally or rapidly build up somewhere beneath the surface of the molten body and subsequently lead to a rapid melt body expulsion. One mechanism, already alluded to above, involves a blockage in the dry zone conduit as a melt progresses downward into more dense material. A slight concavity to the lower surface of the melt body could result in sealing of the melt body to the dense underlying material with a pocket of trapped moisture. Pressure on this trapped water/steam could then build until it exceeds the structural strength of the sintered layer restraining it. If the sintered layer then fails by fracturing, pressurized steam or water would be brought into contact with the molten body with only its hydrostatic head as a restraint. If the sintered layer provides several hundred to thousand psi of strength, the rapid transition to the melt body's $11 \mathrm{psi}$ of restraining force could easily result in a sudden expulsion of molten glass as the bubble rapidly floats to the surface of the melt body or simply displaces glass upwards.

Similar in result, but slightly different in mechanism, would be a failure or cave-in of the sintered layer on the side wall of the melt body. Here, the fracture, in addition to being caused by steam pressure, could be caused by the collapse of subsidence crater wall material. If a ledge of surrounding soil were undercut by an ISV melt growing outward as it progressed downward, beam failure of such a ledge could propagate a crack downward into the side wall of the sintered and/or dry zone material. Such a fissure could occur at any depth of the side wall. An open fissure would be rapidly filled by any perched groundwater outside the dry zone. The molten material could also flow into the fissure, but its high 
viscosity, compared to water, would result in most of the fissure being filled with water rather than melted soil. The rapid contact between liquid water and molten soil could result in the rapid production of steam at high pressure, which could rapidly displace molten material upwards. Failure of the sintered zone beneath the melt could also result in a similar rapid influx of water and subsequent steam generation and melt expulsion.

The observation that the perched groundwater, observed in the two water level monitoring wells within pit 1 just to the north and south of the off-gas hood, was not present on the day after the expulsion incident (Fig. 10) is good evidence that this water was rapidly transported into the melt region. As can be observed from Fig. 10, at the time of the expulsion incident, the bottom of the ISV melt body, as inferred from the depth of electrode penetration, was approximately $10 \mathrm{ft}$ lower in elevation than perched groundwater in pit 1 on the north and south sides of the hood. Thus, the hydraulic gradient was quite steep for movement of water into the region of the melt body during the entire period of melting at pit 1. However, it is unknown whether water movement to the melt body was the result rather than the cause of the expulsion incident. If the expulsion event was caused directly by a trapped pocket of moist soil beneath the engulfing melt body, then the fracturing pressure could create a conduit for water into the melt after the actual causative event. Subsequently, this water could contribute to the magnitude of the event and/or be transported into the dry zone where normal venting could evaporate most of it.

\section{ROOT CAUSE OF PIT 1 MELT EXPULSION INCIDENT}

The root cause of the melt expulsion incident was an inadequate design for project operations. The melt expulsion incident was clearly not considered very probable and, thus, its potential effects were not addressed in either the equipment design or the project procedures. All safety analyses addressed only radiological, electrical, and existing equipment hazards (Spalding and Naney 1995, Campbell and Ikenberry 1990, Lamar and McLaughlin 1987).

Although similar melt expulsions events had been experienced in 3 of the previous 70 large-scale ISV melts at sites other than Oak Ridge, previous incident investigations have implicated man-made subterranean structures, such as tanks, concrete barriers, or drums, which were thought to constrict the normal flow and dissipation of off-gas around the growing molten body. Off-gas from ISV melts is composed mostly of steam as soil moisture is distilled due to its proximity to the molten body. Pit 1 site characterization investigations eliminated the possibility of man-made structures like concrete floors/walls as well as buried objects like tanks or drums. However, pit 1 was constructed in 1951 by excavation to a strata of dense, unweathered or slightly weathered rock which could have functioned to constrain off-gas (steam) movement around the melt body in the soil-filled pit during ISV.

Although several corrective actions are planned to minimize the possibility of melt expulsion events in future ISV operations at ORNL pit 1, the design basis for all future ISV operations must be a melt expulsion event similar in nature but probably larger in size than that experienced on April 21, 1996. Operating procedures must address this design basis to protect both personnel and equipment while also attempting to minimize the probability of its recurrence. 


\section{TECHNIQUES TO AVOID FUTURE MELT EXPULSIONS}

Several techniques have the potential to prevent a repeat of the melt expulsion incident during future ISV operations at pit 1. Several techniques of potential value are listed along with a discussion of their potential effectiveness, feasibility of implementation, and implementation schedule, where available, for subsequent operations at pit 1.

\subsection{DRAWDOWN PERCHED GROUNDWATER IN PIT 1}

As discussed previously in the discussion of the mechanism of the melt expulsion, perched groundwater was, at worst, a likely cause of the driving force for water entering the melt body perimeter, and, at least, a major contributor to the magnitude of the melt expulsion. Future ISV operations should have a hydraulic gradient for gravitational water movement away from, not towards, the melt body. Thus, the perched water table in pit 1 must be drawn down below the target and final depth of the melt body (electrode penetration depth).

Drawdown wells will be installed near, but outside, pit 1 . Aside from the obvious advantage of drilling wells into comparatively uncontaminated soil and having drawdown wells out of the way of the ISV melt bodies, such a placement would likely greatly attenuate the radioactive contamination in the groundwater removed from pit 1 . Groundwater would be drawn into the wells from pit 1 , and all other directions as well, by the drawdown-induced hydraulic gradient. The groundwater from pit 1 would flow through the volume of soil between the pit and the drawdown points where soil adsorption would remove all the ${ }^{137} \mathrm{Cs}$ and most of the ${ }^{90} \mathrm{Sr}$.

Of course, such adsorption is merely an accelerated groundwater movement through pit 1 but in an unnatural direction. However, the drawdown time for such a wells depends on the hydraulic conductivity and connectivity of the formation and the potential location of the well. Such information could be readily determined by drawdown and recharge tests using these new wells at the site. Based on these pump out tests, the size, location, number, and waste disposal characteristics for drawdown can be determined. A minimum of two productive wells to a minimum depth of $35 \mathrm{ft}$ below present grade would be required.

\subsection{EMPLACE MONITORED VENT PIPES BENEATH MELT BODY}

Although the pit 1 initial ISV setup employed straight vent pipes placed at angles to various depths and at various distances from projected growing melt bodies, the zone of pit 1 immediately above the undisturbed pit bottom was not accessible by the selected venting technique. Perhaps pertinently, this was the zone where the melt body bottom was at the time of the melt expulsion. The "unventability" of this depth interval by the selected technique results from the combination of angled, straight vent pipes, the requirement for vent termination inside the off-gas hood, and the impenetrability of the undisturbed pit bottom to drive rods. Had vent pipes been able to be positioned deeper than the pit's undisturbed bottom, viable venting from this depth interval could reasonably have been expected. But, since vent pipes could not be placed through this dense pit bottom, the only option for a venting technique would have been to drive vent pipes at a near horizontal angle which would have necessitated extremely long vents penetrating the soil surface well outside the off-gas hood perimeter. 
Two improvements in subsurface venting techniques will be implemented in future operations at pit 1. First, curved vent pipes will be installed beneath or, at least, at the final melt body depth. These could be emplaced using the same drill rod driving, withdrawal, and final pipe placement methods as used previously. Curved vent pipes would only be required near the bottom of the melt zone while shallower zones could be vented using the previous straight but angled vent pipe technique as previously.

Obviously, vent pipe construction and placement techniques would need to be verified prior to use at pit 1. Previous LMES investigation of directional drilling techniques (ORNL/ER-335, 1995) has neither demonstrated a directly applicable technique nor identified a probable alternate directional drilling strategy which would work at pit 1 ,given the characteristic depth and density of the pit bottom.

Equally important as a credible venting technique for all zones under the melt body is a verification technique that vent pipes are open and remain functional during melt operations. In the previous pit 1 ISV operations, vent pipe performance monitoring became impossible. Ceramic socks were attached to each vent pipe, and it was planned to use the video images of the inside of the hood to determine whether the socks inflated during operations and, hence, were functional in conducting off-gas from the subsurface. However, not only were the video images unable to observe any wind socks, but attempts to view the socks through the observation windows provided a view of only one sock. Thus, vent pipe operational verification was completely unobtainable by the previous technique.

When the off-gas hood is finally moved, observation of any surviving vent pipes and attached socks may provide some fortuitous evidence, e.g., continued venting of hot gas or residual open intervals to final melt body contact, that venting did occur during operations. However, a much more reliable vent pipe performance verification technique needs to be developed. Some type of inexpensive and durable flow sensor could probably be incorporated into the vent pipe to provide some remote signal of gas flow and temperature. Alternately, a tube could be placed inside the vent pipe which is connected to a pressure transducer at the surface; a pressure differential between the point within the pipe tube and the hood plenum would directly proportional to gas flow in the vent pipe.

\subsection{SUBSURFACE PRESSURE MONITORING}

Besides improved venting techniques and remote sensor verification of their operation, it would also seem prudent to development and implement a technique to measure gas pressure beneath the melt body, particularly in the transition zone between fill and dense undisturbed material at the pit bottom. Regardless of vent pipe operation, such monitoring information could provide early warnings to ISV operators that pressures under the melt were building and electrical power should be attenuated in response.

Reduction in melt power, when approaching the pit 1 bottom, is a strategy (discussed below) similar to that used by Geosafe when ISV melts have approached a subsurface concrete barrier. A steel tube, either opened or screened on the end, would be sufficient to transmit pressure to a surface location where an appropriate transducer could be attached in a less harsh environment. Again, through angled and/or curved tube placement, pressure monitoring access points could be positioned at various depths under the projected melt body. Detailed site-specific designs need to be developed and implemented to provide ISV operators with real-time information on subsurface pressures. 


\subsection{HOLD ELECTRODES ABOVE PIT BOTTOM}

When the electrodes and, hence, the melt bottom approach the pit 1 dense undisturbed layer, the electrodes could be held from further penetration and power reduced to the melt. Both of these techniques have been used by Geosafe Corp. in operations at their Salt Lake City site after a similar melt expulsion incident. That site had a relict buried concrete floor under the projected melt zone. After the melt expulsion incident, an additional 35 large-scale melts were performed without incident by employing this technique. ORNL pit 1 may have a similar effective "floor" problem at the pit bottom. Such techniques are designed to slow steam generation while maintaining melt progress near such transition zones. By itself, such a technique has no guarantee to prevent future melt expulsions at pit 1 , but in combination with the techniques discussed above, particularly subsurface pressure monitoring, has excellent potential to minimize recurrence of the problem. The project test plan and operational procedures will be modified to accommodate this approach at minimal cost, perhaps only a few extra days of melt operation.

\section{SAFETY IMPROVEMENTS FOR FUTURE ISV MELT EXPULSIONS}

Even with implementation of all the techniques discussed in the previous section to prevent ISV melt expulsions, the degree of understanding of melt expulsion mechanism is not sufficient to assure that it will not occur again. Thus, more attention must be paid to the inherent risk of a recurrence of the melt expulsion incident. First and foremost, personnel must be protected from injury during performance of necessary tasks in the danger zone around the off-gas hood. Second, protection of ISV equipment on or around the hood should be made sufficient to withstand a similar episode without the degree of damage incurred in this melt expulsion incident and to maintain its functional status.

\subsection{PERSONNEL SAFETY CHANGES}

The various tasks, performed by ISV operations personnel on and around the off-gas hood, are discussed below. Some tasks can be eliminated by providing remote monitoring or adjustment capability outside the danger zone, some tasks can be performed outside a well defined and confined danger zone, and some tasks can be performed within the danger zone using appropriate protective devices discussed subsequently.

\subsubsection{Predetermined Pressure Relief Zones}

The greatest danger zone during the current melt expulsion incident was on the ground surface around the perimeter of the hood; the jetting of hot off-gas and flow of molten material occurred in this zone. Unfortunately, many hood control and monitoring points are mounted on the superstructure base frame clearly within this danger zone. But the danger only occurred where the hood lifted, notably on the north side; virtually no damage occurred on the west side. Thus, design of blowout panels or pressure relief structures might be able to confine the hot off-gas to a predetermined section of the hood perimeter for subsequent melts. Alternately, pressure relief structures might be capable of venting off-gas upwards away from any possibility of contacting operators. If a maximum credible event design basis should demonstrate that engineered structures for off-gas venting are not feasible, then venting techniques, allowing hood lifting, may be considered. 


\subsubsection{Off-Gas Deflection Barrier}

One of the fortuitous consequences of the off-gas jetting out from under the hood on the north side was the presence of a steep slope between the hood and the off-gas control trailer where the pit surface had been graded down approximately $4 \mathrm{ft}$. This steep slope functioned to divert the hot off-gas jet up into the atmosphere rather than into the side of the trailer. The singed grass on the top of this embankment left a direct record of this deflection of hot gas. This fortuitous result points to the effectiveness of deflecting expelled off-gas from horizontal flow where the potential for personnel injury is greatest. Thus, a perimeter deflecting structure can be used as a secondary confining barrier for uncontrolled offgas release and function to protect personnel from injury. The barrier itself could be made of concrete, steel, or earthen materials. Its function as a safety feature will necessitate a detailed engineering evaluation of its effectiveness. A deflection barrier would seem a prudent feature for future ISV operations in addition to any pressure relief vents in case the venting design should prove inadequate for some large-magnitude unpredictable event.

\subsubsection{Elimination of Tasks in Danger Zone}

Operation of the MAS, previously performed by project staff within the danger zone around the hood, will be eliminated in future operations. The MAS was only used at pit 1 after the OAT as a test of its capability to add material under ISV conditions. Approximately, one hopper (2 $\left.\mathrm{yd}^{3}\right)$ load of limestone gravel was added. It was anticipated that significant amounts of limestone would be added throughout the OAT to maintain a lower ISV operating temperature to minimize volatilization of ${ }^{137} \mathrm{Cs}$ during the subsequent melt 1 operations into the contaminated layer of pit 1 . However, the melt appeared to be operating at relatively low temperature $\left(1600^{\circ} \mathrm{C}\right)$ which was ascribed to the relatively large amount of sodium and potassium included in the feldspar starter sand used to initiate this first melt. Thus, the use of feldspar starter sand will be employed in future pit 1 ISV melts and will eliminate the need for the MAS to add limestone.

The MAS was also used to add 4,800 lb (nominally $87 \mathrm{ft}^{3}$ ) of Firelite $2855 \mathrm{LI}$ insulating aggregate after the end of the OAT in an effort to test the concept of an in situ floating barrier/filter on reducing ${ }^{137} \mathrm{Cs}$ volatilization from the melt. This floating layer was to be sampled after the termination of melt 1 ; however, the melt expulsion eliminated this layer although it may have already been incorporated into the melt body. This aggregate is a $60: 40$ (weight basis) alumina:silica high temperature $\left(1540^{\circ} \mathrm{C}\right.$ ) light granular material that had been found to dissolve very slowly into pit 1 molten soil. However, the excellent results observed for the behavior of ${ }^{137} \mathrm{Cs}$ in the pit 1 ISV test preclude the need to add this insulating aggregate to the melt surface using the MAS. Thus, use of the MAS will be eliminated as a task during ISV operations. The MASW has been removed from the hood.

Another task that can be eliminated to avoid the need for ISV operators to enter a danger zone is the recharge and adjustment technique for the hood's water spray suppression system. The system had been disabled from automatic process control during the melt 1 phase of ISV operations. It would have been of little or no use in avoiding, mitigating, or recovering from a melt expulsion event of the magnitude experienced by this project. Thus, use of the internal water spray suppression system will be eliminated and, thus, all tasks related to its use and maintenance.

\subsubsection{Automation of Monitoring and Adjustment Tasks}

Several operator tasks involve gathering data from instruments, checking dial or indicators, and adjustments to equipment within the danger zone around or on the hood. Most of these can be eliminated 
by the use of remote sensors or adjustment controls. Such changes in design of existing equipment or project methods include:

- Use of pressure transducers in groundwater level monitoring wells in the danger zone. Previously, an operator walked to the two monitoring wells on each side of the hood and lowered an electronic tape down the well until it encountered the standing water when a audible signal was initiated. The operator manually recorded the depth of the water on a project data sheet. A pressure transducer can be positioned in the bottom of the well and an electric signal routed back to a remote data acquisition system. Such a system, in addition to completely eliminating the danger to the ISV operator, will result in continuous and automatic data gathering.

- Roughing filter blowback adjustments - Controls for the roughing filter blowback interval, duration, and high and low differential pressure limits can be moved from their present position on the hood frame to a remote pendant, which can be positioned outside the danger zone like the electrode hoist remote pendant. The extension of electric lines would be relatively easy but flexible pipes/lines for the pressure gauge may require some design consideration. Likewise, both the roughing filter's supplied compressed air dial and regulator will need to be moved for remote operation if their adjustment is anticipated to be more frequent than electrode section addition (i.e., more than three - times during a melt).

- Off-gas sampler/monitor - The present Graseby-Andersen paper tape sampler and monitor of the ISV off-gas is attached to the south superstructure frame. An ISV operator visually inspected this apparatus three times a shift. The entire sampler/monitor can be moved outside the danger zone. This will require the extension of the insulated sampling tube ( $0.5 \mathrm{in}$. stainless steel) to the new location and a supply of 110-volt power. Only a few hours of pipe fitter and electrician labor should be required. However, part of the repair of this monitor will include replacement of the burned insulation on the previous sample line between the roughing filter and the edge of the hood

- Air-compressor reset and adjustments - The reset button switch and the air compressor on the west side of the hood can be moved to a remote location using a cable extension and sealed switch. This will eliminate the need for an ISV operator to enter the danger zone for this simple task. If adjustments to the compressor's upper and lower pressure set points are required during operation, then this control box will need to be moved outside the danger zone also. To maximize protection to this equipment as well as to protect operating personnel, the entire air-compressor was moved off the hood to a remote location with the compressed air delivered to the hood via a flexible line.

- Turning lights on and off - Remote switches for the hood's overhead lights and for the lower or window lights will need to be provided. This will eliminate the need for operators to approach the circuit breaker panel attached to the east side of the hood frame. Likewise all 480- and 110-volt breakers should be either opened or closed prior to and not changed during operation. Addition of remote switches will eliminate the use of circuit breakers as switches

- Video camera adjustment and window cleaning - The present video viewing system was grossly deficient in meeting its stated objectives. Obviously, the air-jet window cleaning technique did not function. The manual window cleaning operations used during pit 1 ISV operations cannot be allowed during future operations. In addition to replacement of existing video cameras with ones of proper viewing angle and focus and an automatic iris to accommodate the variation in melt light emission, a remotely controlled window cleaning system must be developed. Electric wiper window systems or rotating window systems are available for many kinds of chemically and thermally harsh environments and should be employed for future ISV monitoring. Testing of the selected window cleaning technique needs to be completed under similar environmental conditions to those experienced or anticipated on the ISV hood. Monitoring of the melt body surface for motion, 
turbulence, bubbling, and brightness provide ISV operators with valuable information on melt behavior. Had a video monitoring system be operable during the present melt expulsion incident, extremely valuable information about the size, location, and kinetics of the expulsion event may have been obtained. Positioning of a video camera directly over the melt may also need to be reconsidered because this puts the camera in a very vulnerable position for thermal stress. The importance of video imaging for ISV operations is such that redundant cameras should be considered to assure continuity of visual monitoring.

- Radiation surveys - Surveys of radiation dose readings by radiation protection personnel walking around and on the hood work platform will be eliminated. Results of the present melting operations have indicated that no contamination was observed outside the hood during operations (excluding the expelled glass product after the incident). Continued confirmation of the lack of surface contamination during ISV operations does not seem worth the risk to personnel safety. Both dose readings and surface smears will be obtained using an extended probe arm from outside the danger zone, i.e., from behind the off-gas deflection barrier.

\subsubsection{Protection of Personnel During Necessary Tasks}

The major task that requires operating personnel to enter the danger zone is the addition of electrode sections. The present design of the electrode hoist system allows only enough room for an extension of one 6-ft long graphite section above the hood penetration point. Thus, after a melt has proceeded downward the length of one electrode section or when an electrode column breaks, operating personnel must perform this task on the hood work platform. The hoist is disconnected from the electrode column in the melt and used to hoist and attach another section onto the existing column. The electrode stop and electrical power contact are then adjusted up to the top of the new electrode section.

The operation requires 3 persons about $30 \mathrm{~min}$ to complete a single electrode section addition; the operations require bolting and unbolting 8 fasteners per electrode and more than 1 person to lift electrode collars and electrode contactors. It is highly desirable to complete this operation with a minimum time for electrical power shut-off because cold cap formation will ensue and can result in electrode binding at the current position.

The temperature of the work platform environment during the melt expulsion incident must have been quite hot; the hood panels, only a foot below the open grating of the work platform, were reported to be glowing cherry-red (i.e., $>1000^{\circ} \mathrm{C}$ ). Workers in such a situation will need thermal protection for the conservative period of $20-40$ seconds required to effect a controlled walk exit from the platform to outside the danger zone. Thermal protective suits would seem to offer such protection; consultations with safety specialists have been initiated to determine the best personnel protective clothing to procure for this situation. Likewise, emergency repairs to hood equipment, which cannot be delayed until scheduled downtime, will require the use of such protective equipment by any personnel in the danger zone.

Several changes in electrode addition procedure will be made to minimize the time necessary on the hood's work platform. First, because a typical melt requires three electrode sections, these sections should be staged on the work platform rather than the previous staging area on the ground surface to the north and south of the hood. These previous staging areas were clearly in some of the most hazardous locations for off-gas jetting during a melt expulsion. The use of hood pressure vents may make these areas less hazardous but cannot completely eliminate the danger to personnel anywhere on the hood perimeter. 
Second, power nut drivers will be used to replace the previous hand wrenches to reduce the time spent bolting and unbolting fasteners. Galling of bolt threads in the sometimes warm hood environment often made bolt loosening and tightening a difficult and time-consuming task. Alternate types of quickconnect fasteners will also be considered to replace these bolts.

Third, a complete set of four electrode additions will be made at one time; to facilitate this timing in electrode additions, leading electrodes will be held on their stops until lagging electrodes catch up. There is an inherent increase in task efficiency and consequently decrease in time per electrode addition if one crew can perform all electrode additions at one time. This will be particularly true when power tools reduce the fatigue factor during bolt loosening, which necessitated personnel task sharing during several electrode additions.

\subsubsection{Definition of Hazard Zones and Times}

It is virtually impossible to predict in an objective theoretical manner an interval of time after shutdown of electrical power to an ISV melt when a melt expulsion incident cannot occur. Such a situation is not too surprising when one considers the scientific efforts and resources that have been invested into predicting natural volcanic eruptions that have met with very limited success, at least at the time resolution of seconds required for ISV responses. Obviously, as time passes after electrical shutdown, an ISV melt body cools and its surfaces solidify at some point to a strength where its molten interior can no longer move or be expelled.

It is hoped that the subsurface pressure monitoring technique will provide some objective data from which decisions about personnel entry to the hood platform can be made. Criteria, e.g., the pressure must be stable for at least $1 \mathrm{hr}$ and be below a certain threshold before entry can be attempted, could be used. An analogous decision about when the off-gas processing system can be shut down following power termination after a melt has resulted in a generally accepted conclusion that $\sim 4 \mathrm{hr}$ are required before hazardous or radioactive contamination of off-gas can no longer be detected; this rule-of-thumb has been ascribed to the time required for the surface of the melt body to form a sufficient cold cap to eliminate further contaminant release from the melt. Perhaps a similar rule-of-thumb can be deduced for hardening of the melt body's sintered shell, which would preclude the possibility of a melt expulsion. Such rules-ofthumb will likely evolve in the future. But the resumed ISV operations at pit 1 will attempt to devise an indicator of melt stability from submelt pressure measurement. For the foreseeable future, personnel will require protective clothing or equipment whenever they enter the danger zone.

Other indicators of approaching melt expulsion events have been suggested in previous incidents. These include electrical power fluctuations, unusual melt surface bubbling, and antecedent minor hood pressurizations. None of these possible indicators has a definitive threshold for predicting melt expulsion events. In future ISV operations at ORNL, improved techniques to monitor these possible indicators will be attempted and operating personnel will be trained for their recognition. However, whether these indicators can be observed adequately, recognized in time to take action, or whether those actions, i.e., reduction in melt power, can avoid an expulsion is not known.

The hazard or danger zone around the ISV hood will be maintained at the planned electrical safety exclusion zone, i.e., $20 \mathrm{ft}$ or other arbitrary distance away. However, an off-gas deflecting barrier will be constructed at or inside this boundary. A mandatory exclusion zone will be maintained immediately outside any pressure relieving venting structure. These zones will be marked with the entrance requirements and danger indications. 


\subsection{EQUIPMENT PROTECTION}

It would be quite expensive to relocate all of the hood's vulnerable equipment outside the danger zone. However, mostl of the damage to the equipment on the hood's superstructure base was caused by secondary fires. Thus, removal of all possible combustible material from the danger zone would greatly minimize most of the secondary fires. Items such as wooden cribbing and fiberglass grate walkways would be quite simple to accomplish.

Other thermal damage was caused by proximity to expelled molten glass. Items such as electrical conduit, hydraulic lines, electrical junction and circuit breaker boxes and instrument housings can be protected by being wrapped in high temperature insulation, particularly on their bottom and inside surface where most of the paint scorching has been observed. Electrical cords and sensor signal wires on the hood work platform will also be insulated to protect them against the relatively short duration thermal insult of such a melt expulsion. Tires can be protected by rigid thermal insulation boards or removal. Additional insulation of the superstructure's main beam and components will be placed around areas near any venting structures on the hood.

In addition to insulation and/or removal of peripheral equipment, a great deal of damage could have been prevented by the use of a small soil berm inside the hood to contain molten material flow from contacting the hood walls and flowing out underneath. Such containment would prevent much of the thermal warping of hood panels and the secondary fires on the southeast corner of the hood which were caused by direct contact with molten glass.

A hood-cooling external water spray system, similar to that designed by Geosafe Corp. for their ISV off-gas hood, could provide excellent equipment protection. The Geosafe spray system does not function to cool hood panels but only to propel mist into the air surrounding the hood, thus, cooling and preventing combustibles from igniting. Such a system would need to deliver a significant volume of water and be manually activated by operations personnel in response to predetermined criteria.

The roughing filter needs to be protected in future melt operations because, whether or not the hood leaves the ground in future melt expulsions, the roughing filter will likely sustain similar damage. Practically all the 128 filter elements were splashed with molten glass, which adheres well to the ceramic fabric. More importantly, when sampling the fabric, it was found to be extremely brittle and friable. One could poke a finger through it just in attempting to hold the filter. Initially, the fabric was quite flexible and durable; when sampled after the OAT, it was still quite strong and not noticeably brittle or friable. Nextel fabric has a stated temperature resistance of $1204^{\circ} \mathrm{C}$ for short duration and $760^{\circ} \mathrm{C}$ for continuous use. It is not known whether the brittleness of the ceramic fabric after the event was the result of their proximity to and contact by molten glass or a result of the general thermal surge within the hood. Regardless, the roughing filter bags need to be protected from melt splashes in the future. If the redesigned hood can vent off-gas well, i.e., not lift off the ground, and also endure the thermal shock without damage to wires, air, and hydraulic lines, then a possible down time of several weeks simply to replace damaged roughing filter bags, which would be covered with radioactive glass, would not be justifiable.

\subsection{EMERGENCY RESPONDER TRAINING AND PROCEDURES}

The major consideration in the decision to advise the emergency responders (firemen) not to fight the secondary fires around the hood perimeter was the uncertainty in radioactive emissions and contamination of external hood surfaces at the time. It seemed logical that pouring water on these very 
hot surfaces would result in rapid steam generation and an unknown potential for entrainment of radioactive contamination into the subsequent plume of steam. Having determined the degree of radioactive contamination after the incident, such fire fighting efforts even with water could have saved a great deal of equipment damage with little or no effect on radioactive contamination containment. Even a better fire-fighting strategy could have employed carbon dioxide extinguishers on the several small fires that caused much of the electrical insulation damage. Thus, in the unlikely event of future fires, fire fighters will be briefed on materials and methods for fighting such fires. They will also be briefed on the maximum radioactive contamination conditions to which they may be exposed.

In addition, the decision to turn off all power to the site for the hood perimeter fire was not wise for the protection of equipment or minimization of environmental contamination. Again, the decision was made for the protection of fire fighting personnel. In virtually the same amount of time required to open the line circuit and turn off the emergency generator, power to the hood blower and the hood system could have been shut down at the control trailer; the off-gas system could thus have continued in operation. Power to the electrodes was already shut off by the shift engineer's action of pushing the emergency power switch. With shut off of three switches, all power to the hood would have been off and fire fighting efforts could have proceeded without fear of electrical hazards. These conclusions will be incorporated into the modified emergency plan for the project.

\section{REFERENCES}

Battelle Pacific Northwest Laboratory. 1995. In Situ Vitrification Large-Scale System Safe Operating Procedure. Procedure 58, Revision 9. Battelle Pacific Northwest Laboratory, Richland, Washington, 69pp.

Campbell, B. E. and T. A. Ikenberry. 1990. Safety Evaluation Document for the 116-B-6A Crib ISV Demonstration Project. Battelle Pacific Northwest laboratory, Richland, Washington.

Environmental Restoration Program. 1995. Technical Report for a Fluidless Directional Drilling System Demonstrated at Solid Waste Storage Area 6 Shallow Burial Waste Sites. ORNL/ER-335. Lockheed Martin Energy Systems. Oak Ridge, Tennessee.

Geosafe Corporation. 1993. Summary Report. Investigation into the causes and application significance of the melt displacement event occurring during Geosafe operational acceptance test \#2. Geosafe Corporation, Richland, Washington.

Lamar, D. A. and T. J. McLaughlin. 1987. Safety Analysis Documentation Large-Scale Radioactive Testing of the In Situ Vitrification Process at the 216-Z-12 Crib. Battelle Pacific Northwest Laboratory, Richland, Washington.

Roberts, B. M., W. J. Apley, J. L. Bates, S .S. Koegler, D. E. Knowlton, W. D. Richmond, and J. W. Smith. 1991. ISV Pressurization Incident Final Report of the Investigation Committee. Pacific Northwest Laboratory, Richland, Washington.

Roberts, J. S., D. L. Lessor, S. L. Woosley, and C. Strachan. 1992. Preliminary investigation of the potential for transient vapor release events during in situ vitrification based on thermal-hydraulic modeling. PNL-8170. Battelle Pacific Northwest Laboratory, Richland, Washington. 
Shade, J. W. and G. F. Piepel. 1990. Viscosity, electrical conductivity, and cesium volatility of ORNL vitrified soils with limestone and sodium additives. PNL-7331. Pacific Northwest Laboratory, Richland, Washington.

Shaw, H. R. 1972. Viscosities of magmatic silicate liquids: An empirical method of prediction. Amer. J. Sci. 272: 870-893.

Spalding, B. P. and G. K. Jacobs. 1989. Evaluation of an in situ vitrification field demonstration of a simulated radioactive liquid waste disposal trench. ORNL/TM-10992. Oak Ridge National Laboratory, Oak Ridge, Tennessee.

Spalding, B. P., G. K. Jacobs, N. W. Dunbar, M. T. Naney, J. S. Tixier, and T. D. Powell. 1992. Tracer-level radioactive pilot-scale test of in situ vitrification for the stabilization of contaminated soil sites at ORNL. ORNL/TM-12201. Oak Ridge National Laboratory, Oak Ridge, Tennessee.

Spalding, B. P. and M. T. Naney. 1995. Site Safety and Health Plan (Phase III) for the Treatability Study for In Situ Vitrification at Seepage Pit 1 in Waste Area Grouping 7 Oak Ridge National Laboratory, Oak Ridge, Tennessee. ORNL/ER-314. Lockheed Martin Energy Systems, Inc., Oak Ridge, Tennessee. 


\section{DISTRIBUTION}

1. L. V. Asplund

2. J. A. Blair

3. M. A. Bogle

4. W. D. Brickeen

5. C. Clark, Jr.

6. S. R. Cline

7. R. B. Cook

8. B. E. Copeland

9. R. C. Farr

10. S. A. Hamley

11. L. S. Hawk

12. W. C. Hayes

13. S. G. Hildebrand

14. J. B. Hunt

15. G. K. Jacobs

16-17. D. M. Matteo

18. L. W. May

19. M. T. Naney

20-21. P. T. Owen

22. D. E. Reichle

23. D. G. Renfro

24. D. G. Rowland

25. P. A. Schrandt

26. I. M. Smith

27-36. B. P. Spalding

36-45. V. L. Turner

46. Central Research Libiary

47. ER Document Management Center-RC

48. R. A. Brouns, Battelle Pacific Northwest National Laboratory, Battelle Boulevard, Richland, Washington 99352

49. J. L. McElroy, Geosafe Corporation, 2950 George Washington Way, Richland, Washington 99352

50. C. L. Timmerman, Geosafe Corporation, 2950 George Washington Way, Richland, Washington 99352

51-60. J. S. Tixier, Battelle Pacific Northwest National Laboratory, Battelle Boulevard, Richland, Washington 99352

61. S. L. Woosley, Geosafe Corporation, 2950 George Washington Way, Richland, Washington 99352

62-63. Office of Scientific and Technical Information, P.O. Box 62, Oak Ridge, TN 37831 